\title{
Modification of the Predicted Heat Strain (PHS) model in predicting human thermal responses for Chinese workers in hot environments
}

Article

Accepted Version

Creative Commons: Attribution-Noncommercial-No Derivative Works 4.0

Du, C., Li, B., Li, Y., Xu, M. and Yao, R. (2019) Modification of the Predicted Heat Strain (PHS) model in predicting human thermal responses for Chinese workers in hot environments. Building and Environment, 165. 106349. ISSN 0360-1323 doi: https://doi.org/10.1016/j.buildenv.2019.106349 Available at https://centaur.reading.ac.uk/86708/

It is advisable to refer to the publisher's version if you intend to cite from the work. See Guidance on citing.

To link to this article DOI: http://dx.doi.org/10.1016/j.buildenv.2019.106349

Publisher: Elsevier

All outputs in CentAUR are protected by Intellectual Property Rights law, including copyright law. Copyright and IPR is retained by the creators or other copyright holders. Terms and conditions for use of this material are defined in the End User Agreement. 


\section{CentAUR}

Central Archive at the University of Reading

Reading's research outputs online 
Building and Environment 165 (2019) 106349

Modification of the Predicted Heat Strain (PHS) model in predicting human thermal responses for Chinese workers in hot environments

Chenqiu Du ${ }^{\mathrm{a}, \mathrm{b}}$, Baizhan $\mathrm{Li}^{\mathrm{a}, \mathrm{b}, *}$, Yongqiang $\mathrm{Li}^{\mathrm{a}}$, Mengnan $\mathrm{Xu}^{\mathrm{a}}$, Runming $\mathrm{Yao}^{\mathrm{a}, \mathrm{c}, * *}$

a Joint International Research Laboratory of Green Buildings and Built Environments (Ministry of Education), Chongqing University, Chongqing, 400045, China

'National Centre for Intermational Research of Low-carbon and Green Buildings (Ministry of Science and Technology), Chongqing University, Chongqing, 400045, Chin 'School of the Bullt Environment, University of Reading, Reading, RG6 6DB, UK

\title{
Modification of the Predicted Heat Strain (PHS) model in predicting human thermal responses for Chinese workers in hot environments
}

\begin{abstract}
The Predicted Heat Strain (PHS) model predicts physiological responses of European people to heat stress; while its performance for Chinese population remains underexplored. The study conducted a heat exposure experiment (temperature: $35{ }^{\circ} \mathrm{C} / 38{ }^{\circ} \mathrm{C} / 40{ }^{\circ} \mathrm{C}$, relative humidity (RH): $\left.25 \% / 40 \% / 60 \%\right)$ in a well-controlled climate chamber. 10 male Chinese workers were recruited to perform exercises on the treadmill at a speed of $0.5 \mathrm{~m} / \mathrm{s}$ for $120 \mathrm{~min}$, to simulate moderate metabolic rate. Rectal temperature(Tre), skin temperature(Tsk), sweat $\operatorname{rate}(\mathrm{SR})$ and heart rate(HR) were monitored continuously; the corresponding predicted values were obtained by the PHS model. The results showed that the measured Tre, Tsk, SR increased significantly with increased temperature and humidity. The PHS model overestimated the maximum allowable exposure time of subjects but underestimated the final Tre and Tsk. BlandAltman analysis showed that the differences and 95\%CI between the observed and predicted values increased with increasing temperature and $\mathrm{RH}$ and exposure time, indicating the significant prediction deviation of the PHS model. Through adjusting the initial Tre from $36.8{ }^{\circ} \mathrm{C}$ to $37{ }^{\circ} \mathrm{C}$, the protection efficacy was improved from original $24.7 \%$ to $57.1 \%$ for the PHS model. The protection efficacies were further improved to $71.2 \%$ through adjusting the maximum HR based on ages, and to $68.2 \%$ through adopting the real-time HR to predict metabolic rates. The proposed three methods improve the heat strain prediction in the PHS model for Chinese workers and are more applicable in practical hot working place. This benefits to policy decisions and
\end{abstract}


occupational safety protection for Chinese workers with heat exposure risks.

\section{Keywords:}

Hot environments; Heat stress; PHS model; Physiological responses; Bland-Altman analysis; Model modification.

\section{Introduction}

According to IPCC 2014 report, the average global temperature has risen about $0.85{ }^{\circ} \mathrm{C}$ over the past century and projected to increase by at least $3{ }^{\circ} \mathrm{C}$ by 2100 [1]. As global warming is increasing the intensity and frequency of extreme weather events, research attention has focused increasingly on human performance/productivity, heatinduced illness, and human health in a hotter world [2, 3]. For example, heat stress is a potential health hazard in both living and working spaces in hot seasons $[4,5,6]$. People exposed to heat stress can suffer a range of heat illness symptoms, including fatigue, reduced psychomotor performance, loss of concentration and reduced alertness [7]. Particularly, Workers in construction, agriculture, and forestry, and those in hot indoor working environments such as manufacturing, mining and steel industries are the most vulnerable to the adverse health effects of heat exposure $[8,9]$. Records collected by the US Census of Fatal Occupational Injuries showed that construction workers accounted for $36 \%$ of the heated-related fatalities from 2003 to 2008 [10]. Similar data from Hong Kong showed that the incidence of heat stress in construction work has increased and led to several verified reported deaths[11]. In a survey that asked construction workers in Japan about heat related symptoms, $63.7 \%$ workers felt thirsty, and $42.2 \%$ felt fatigued during heat exposure [12]. Although some heat management strategies are available in these fields, their efficacy largely depends on workers' and managers' knowledge and willingness to hold to prevention strategies [13]. Therefore, suitable heat stress predictions and risk interventions for people working under extremely hot conditions are urgently needed. 
More than 100 indices and models have been developed for evaluating heat stress, and these have varying complexity and applicability [14]. These indices are typically classified into three groups [15]: direct indices that are recorded from direct measurements of thermal environments, empirical indices that are established by using heat transfer equations from physiological responses, and rational indices that are based on the heat balance between a human and the environment. Thermal, empirical and rational indices based on linear equations were reviewed recently, with discussion of the effectiveness of each index for coping with various climatic conditions [16]. Of all the heat stress indices, the wet-bulb globe temperature (WBGT) index is the most widely used [17]. The WBGT index combines several important environmental variables for heat stress assessment $[18,19]$ and its performance has been verified with measurements of microclimate variables [20]. However, the WBGT index is unable to predict human thermal response. Moran et al. [21] proposed a physiological strain index (PhSI) that is better for predicting the overall state of a human's physiological strain; but the PhSI is dominated by the increase of heart rate, and responds slowly changes in core temperature [22, 23]. As researchers develop better understanding of heat exchange between human bodies and the thermal environment, sophisticated and more -accurate rational indices have been formulated [24]. Malchaire et al. [25] first developed the predicted heat strain (PHS) model, which was based on thermal equilibrium of human body. The predicted values of rectal temperature(Tre), skin temperature(Tsk) and sweat rates (SR) are obtained through continuous iteration of the relationship between skin moisture rate, sweat evaporation efficiency, evaporative cooling capacity and maximum perspiration ability. These indicators are more accurate than the required sweat rate (SWreq) model in ISO 7933[26]. Therefore, the ISO 7933 standard adopted the PHS model for predicting heat stress in 2004 [27].

Overall, the PHS model evaluates the degree of heat stress that is likely to lead to excessive core temperature and water loss and includes a method for determining the maximum allowable exposure time within which no physical damage will be sustained. The model was also found to be superior to the WBGT index for defining the severity 
of the potential heat stress $[25,28]$. However, the PHS model was developed using a database of laboratory and field experiments that used European subjects, and its use is sometimes inaccurate in practical contexts. Lundgren-Kownackia et al. [29] compared the predictions from the PHS model and the Fiala's thermophysiological model with subjects performing intermittent work in a hot environment $\left(34{ }^{\circ} \mathrm{C} / 60 \% \mathrm{RH}\right)$. The PHS model tended to over-predict Tre during the first activity period and tended to overestimate the cooling efficiency of sweating during the recovery period, thus underestimating heat strain overall. Bröde et al. [30] compared the estimated workability of three heat stress metrics (i.e. WBGT, PHS, UTCI-Fiala) for work at three intensities (light, moderate, high). The results showed that Tre predictions in the PHS model were higher, and this overestimation was attributed to the model's exclusion of thermal inertia and heat distribution in the body. The rational PHS model is therefore limited by environmental conditions, individual characteristics, climate, population features and other factors $[14,31,32]$. A reliable and accurate evaluation of the PHS model should be developed for predicting human physiological responses in varying conditions.

China is experiencing rapid urbanization process. This shift in population distribution will increase the number of workers who are exposed to heat exposure and the intensity of that exposure. Using a crossover analysis in Guangzhou, China, Ma et al. [33] found that high WBGT was associated with increased work-related injuries, which carrued significant economic costs. Therefore, heat strain must be predicted for Chinese workers in particular, to develop appropriate labour protection strategies and minimize productivity loss. However, the current Chinese standards and specifications for a hot working environment basically track the prevailing ISO standards. Though the PHS is an acknowledged index for human heat strain evaluation, the PHS model was originally established with data about European populations[19, 26, 27], whose physical, psychological, cultural and other social characteristics are quite different from those of Chinese populations. Therefore, we question whether the PHS model is valid with Chinese workers. To the best of the authors' knowledge, the applicability and 
performance of the PHS model for specifically Chinese people has yet to be examined and documented. This examination is urgently needed before the PHS model is promoted widely in China.

The present study aims to give a holistic evaluation of the performance of the PHS model when predicting the physiological responses of Chinese workers to heat. First, observed physiological responses in a simulated heat-exposure experiment in a wellcontrolled climate chamber were compared to the predicted values of the PHS model. Bland-Altman analysis was then employed to assess the agreement between the PHS model prediction and observed responses. Then, potential improvements to the PHS model were assessed through modifications of the initial Tre, maximum HR, and actual metabolic levels. The modified PHS model proves to give better predictions of heat strain in Chinese workers in practical workplaces. These predictions can be used to mitigate the risk to workers in hot environments.

\section{Methods}

A heat exposure experiment was conducted in the laboratory during summer. A climate chamber was used to simulate a hot working environment, and 10 Chinese workers from labour market were chosen and paid to participate in experiments. Subjects were instructed to walk on a treadmill at a certain speed and for a certain time, to simulate practical working conditions under a specific work intensity and time. According to ISO 8996 [34], metabolic rate can be classified into several categories. The average metabolic rate is $165 \mathrm{~W} / \mathrm{m}^{2}$ and moderate metabolic rates range from 130$200 \mathrm{~W} / \mathrm{m}^{2}$ (Class II). Common work activity in daily life fits into this range so these classifications were applied in the present study. To simulate specific work rates, the speed of the treadmill was set to $0.5 \mathrm{~m} / \mathrm{s}$ as specified in ISO 8996 [34]. Experimental observations of subjects' physiological indices of Tre, Tsk, SR and HR were compared with the values predicted by the PHS model. 


\subsection{Experimental designs}

A climate chamber with dimensions of $4 \mathrm{~m}(\mathrm{~L}) \times 3 \mathrm{~m}(\mathrm{~W}) \times 3 \mathrm{~m}(\mathrm{H})$ was used as the hot environments. The range and accuracy of the air temperature in the chamber were $-5-45{ }^{\circ} \mathrm{C}$ within $\pm 0.3{ }^{\circ} \mathrm{C}$; the relative humidity(RH) ranged from $10 \%-90 \%$ within $\pm 5 \%$; air velocity was around $0.1-2 \mathrm{~m} / \mathrm{s}$ within $\pm 0.3 \mathrm{~m} / \mathrm{s}$. During experiments, air was supplied through a perforated plate diffuser in the ceiling so that the air velocity at the work space was around $0.1 \mathrm{~m} / \mathrm{s}$. An adjacent room was climate-controlled to achieve a neutral environment of $26{ }^{\circ} \mathrm{C}$ and was used to prepare the subjects for experimental trails.

Hot environments typically count as a living environments hotter than $35^{\circ} \mathrm{C}$, or a working environment hotter than $32{ }^{\circ} \mathrm{C}$ [35]. When the environment temperature is lower than $35^{\circ} \mathrm{C}$, the body's heat balance can be maintained at rest and evaporative heat loss is close to heat generated in body; when the temperature exceeds $35{ }^{\circ} \mathrm{C}$ and person engages in moderate activity, heat accumulates in the body. Therefore, a hot work environment is usually defined as one in which the dry-bulb temperature is higher than $35^{\circ} \mathrm{C}$, with the single or coupled effects with high radiation and air humidity [36]. The China GB/T 934 standard [37] defines a hot work environment as one with a WBGT index higher than $25{ }^{\circ} \mathrm{C}$. To cover the range of hot environments specified in these standards, we adopted three temperature levels that were higher than $35^{\circ} \mathrm{C}$, with the combination of three RH levels, with which the WBGT was equal to or higher than $25{ }^{\circ} \mathrm{C}$. The designed experimental conditions are listed in Table 1 . Table 1 also shows the mean values measured during experiments: the measured air temperature and $\mathrm{RH}$ were close to the desired conditions, and deviations were less than $0.3{ }^{\circ} \mathrm{C}$ for temperature and less than $5 \%$ for $\mathrm{RH}$. Because of the inner enclosure structure of the climate chamber, the measured black-bulb temperature was close to the dry-bulb temperature during experiments and the difference between these values was less than $0.5^{\circ} \mathrm{C}$. Therefore, radiation effects are ignored in the following analysis. The WBGT index was calculated according to the measured air temperature, relative humidity, and global temperature. The minimum WBGT value was $24.7{ }^{\circ} \mathrm{C}$ at $35^{\circ} \mathrm{C}$ and $25 \% \mathrm{RH}$, and 
increased remarkably as the relative humidity increased. The maximum WBGT value was $34.1{ }^{\circ} \mathrm{C}$ at $40{ }^{\circ} \mathrm{C} / 60 \% \mathrm{RH}$, which is much higher than the WBGT limits recommended by the American College of Sports Medicine (ACSM) [38].

Table 1 Designed conditions and measured parameters in experiments

\begin{tabular}{ccccccc}
\hline Trials & $\begin{array}{c}\text { Conditions } \\
(\mathrm{T} / \mathrm{RH})\end{array}$ & $\begin{array}{c}\text { Dry-bulb } \\
\text { temperature } /{ }^{\circ} \mathrm{C}\end{array}$ & $\begin{array}{c}\text { Global } \\
\text { temperature } /{ }^{\circ} \mathrm{C}\end{array}$ & $\begin{array}{c}\text { Relative } \\
\text { humidity } / \%\end{array}$ & $\begin{array}{c}\text { Air } \\
\text { velocity/m/s }\end{array}$ & $\begin{array}{c}\text { WBGT } \\
\left({ }^{\circ} \mathrm{C}\right)^{*}\end{array}$ \\
\hline $\mathrm{A} 1$ & $35^{\circ} \mathrm{C} / 25 \%$ & $35.1 \pm 0.2$ & $34.5 \pm 0.2$ & $25.9 \pm 3.1$ & 0.09 & 24.7 \\
$\mathrm{~A} 2$ & $35^{\circ} \mathrm{C} / 40 \%$ & $34.8 \pm 0.3$ & $34.4 \pm 0.3$ & $41.1 \pm 2.2$ & 0.09 & 27.1 \\
$\mathrm{~A} 3$ & $35^{\circ} \mathrm{C} / 60 \%$ & $35.0 \pm 0.2$ & $34.6 \pm 0.2$ & $58.9 \pm 3.6$ & 0.09 & 29.8 \\
$\mathrm{~B} 1$ & $38^{\circ} \mathrm{C} / 25 \%$ & $37.7 \pm 0.1$ & $37.5 \pm 0.2$ & $25.4 \pm 2.7$ & 0.08 & 26.7 \\
$\mathrm{~B} 2$ & $38^{\circ} \mathrm{C} / 40 \%$ & $37.8 \pm 0.2$ & $37.4 \pm 0.3$ & $39.6 \pm 2.3$ & 0.13 & 29.3 \\
$\mathrm{~B} 3$ & $38^{\circ} \mathrm{C} / 60 \%$ & $38.3 \pm 0.2$ & $37.6 \pm 0.2$ & $59.1 \pm 1.7$ & 0.09 & 32.7 \\
$\mathrm{C} 1$ & $40^{\circ} \mathrm{C} / 25 \%$ & $39.9 \pm 0.2$ & $39.3 \pm 0.2$ & $25.3 \pm 2.4$ & 0.11 & 28.3 \\
$\mathrm{C} 2$ & $40^{\circ} \mathrm{C} / 40 \%$ & $40.1 \pm 0.1$ & $39.1 \pm 0.3$ & $39.4 \pm 2.8$ & 0.11 & 31.1 \\
$\mathrm{C} 3$ & $40^{\circ} \mathrm{C} / 60 \%$ & $39.9 \pm 0.1$ & $39.3 \pm 0.2$ & $57.9 \pm 2.9$ & 0.09 & 34.1 \\
\hline
\end{tabular}

(Note: WBGT was calculated according to the following formula that does not consider direct sun:

$$
\text { WBGT }=0.7 * \mathrm{~T}_{\mathrm{NW}}+0.3 * \mathrm{~T}_{\mathrm{G}}
$$

where the $\mathrm{T}_{\mathrm{NW}}$ is the natural wet-bulb temperature, which is calculated from the air temperature and relative humidity, ${ }^{\circ} \mathrm{C} ; \mathrm{T}_{\mathrm{G}}$ is the global temperature, ${ }^{\circ} \mathrm{C}$.

\subsection{Subjects}

We recruited subjects from the labour market in Chongqing, China. A standardized questionnaire about health condition was first administered to candidates, so that we could exclude candidates with hypertension, cardiac issue, or serious heat illness. After that, 25 healthy male workers were recruited from the labour pool. All the recruits have more than 10 years of experience in manual labour in Chongqing. Before enrolment in the study, each participant received verbal and written explanation of the experiments and then signed an informed-consent form. This explanation included a briefing on the experimental procedure and instruments, as well as the expected activity on the treadmill.

During the pre-experiment tests, controlled chamber with temperature of $38{ }^{\circ} \mathrm{C}$, relative humidity of $40 \%$ and air velocity of under $0.1 \mathrm{~m} / \mathrm{s}$ was built. Participants were 
asked to walk at $0.5 \mathrm{~m} / \mathrm{s}$ on a treadmill for $60 \mathrm{~min}$ and their physiological indices of Tre and HR were monitored continuously. No subjects showed symptoms indicative of common cold, influenza, fever, or other illness, and none took medication or alcohol during the test period. After the experiments, indices were collected and the mean values and standard deviations were calculated. We took the values of Tre and HR at the end of the pre-tests as baselines and then excluded subjects whose final mean Tre and $\mathrm{HR}$ exceeded the overall mean value $\pm 3 \mathrm{SD}$, to minimize individual differences among participants. Two participates' Tre exceeded the standard and one participant's HR exceeded the standard. For formal experiments, the sample size was first calculated by statistics (a priori power analysis in G*Power software [39]). With designed 9 conditions and male participants, F test and ANOVA were chosen in software. The effect size of $0.8, \alpha=0.05$, and $1-\beta=0.95$ were determined and thus the statistical total sample size was 5. Considering the individual differences, coupled with cost and time of the experiments, this study finally selected 10 of the remaining 22 participants to participate in the formal experiment. Their basic information is listed in Table 2.

Table 2 Basic information for the chosen subjects

\begin{tabular}{ccc}
\hline Basic information & Mean \pm SD & Range \\
\hline Age & $39.4 \pm 3.6$ & $35-48$ \\
Height $[\mathrm{m}]$ & $168 \pm 2.3$ & $164-173$ \\
Weight $[\mathrm{kg}]$ & $59.8 \pm 2.3$ & $55.4-65.6$ \\
BMI index $\left[\mathrm{kg} . \mathrm{m}^{-2}\right]$ & $21.2 \pm 0.7$ & $20.1-22.5$ \\
Resting heart rate $[\mathrm{bpm}]$ & $68.3 \pm 5.7$ & $59-76$ \\
\hline
\end{tabular}

\subsection{Experimental protocols}

The experiments were performed in accordance with the ethical standards of the 1964 Helsinki Declaration [40]. Subjects could terminate the experiment at any time if they felt a little ill, or for any other reasons which would make them unwilling to 
continue. As an additional precaution in line with WHO recommendation [41], if the monitored HR of subjects exceeded 180bpm for three minutes continuously, or Tre was over $39^{\circ} \mathrm{C}$, the test was terminated immediately.

Figure 1 shows a picture of the experiment. The measured parameters and information about the corresponding instruments we used are listed in Table 3.

Subjects were asked to arrive at the neutral-temperature room 30min before tests to eliminate the effect of the outdoor environments and previous metabolic rates. They were asked to change into uniform clothes (short T-shirt, shorts, and shoes, clothing insulation: 0.32clo) and attach thermocouples (Table 3) to the skin surface on the chest, upper arm, left thigh and calf. The thermocouples were fixed using surgical, water permeable, adhesive tape, and were connected to a data logger, which was carried by the subjects during the tests (see Figure 1). Carrying the data logger ensured that subjects could move freely when walking on the treadmill. The mean Tre was calculated using the four-point method, proposed by Ramanathan [42]. The heart-rate sensor (Table 3) was attached to the chest with skin contact, and the heart rate was recorded by a heart rate watch (see Figure 1). The same thermocouple rectal probe was first sterilized and was inserted by the subjects to a depth of $10 \mathrm{~cm}$ above the anal sphincter.

After attaching all instruments and preparing for the tests, subjects entered the climate chamber and the formal experiment began. The whole test lasted 120min. Two sport treadmills (SH-5522) were set up in the climate chamber, with slope at $10 \%$ and a speed of $0.5 \mathrm{~m} / \mathrm{s}(1.8 \mathrm{~km} / \mathrm{h})$. These conditions were designed to simulate typical daily labor, for which the metabolic rate is estimated to be $160 \mathrm{~W} / \mathrm{m}^{2}$ [34]. Before tests, each subject was weighed nude (with underwear) and weighed again after they put on experimental clothes. During tests, subjects walked on the treadmill and were free to drink water. The amount of water intake was recorded. Immediately after each test, the subject was weighed clothed; then he returned to prepared room and was weighed nude after all the perspiration at skin surface evaporated totally. The total water loss was obtained from the changes in body weight before and after the trial and these measurements were corrected for water intake, which follows the work of Machado- 
Moreira[43] and Tian [44]. The obtained values were assumed to be the sweat produced by subjects during heat exposure (i.e. SR).

Over the duration of 120 -min trial, the ambient thermal environment was measured every 10min with a thermal comfort instrument (Table 3). Subjects' local skin temperatures and rectal temperatures were recorded continuously at every $10 \mathrm{~s}$. The acquisition interval was set to $1 \mathrm{~min}$ for recording heart rate by sensors. They were allowed to terminate the exercise when one of the above-mentioned conditions occurred.
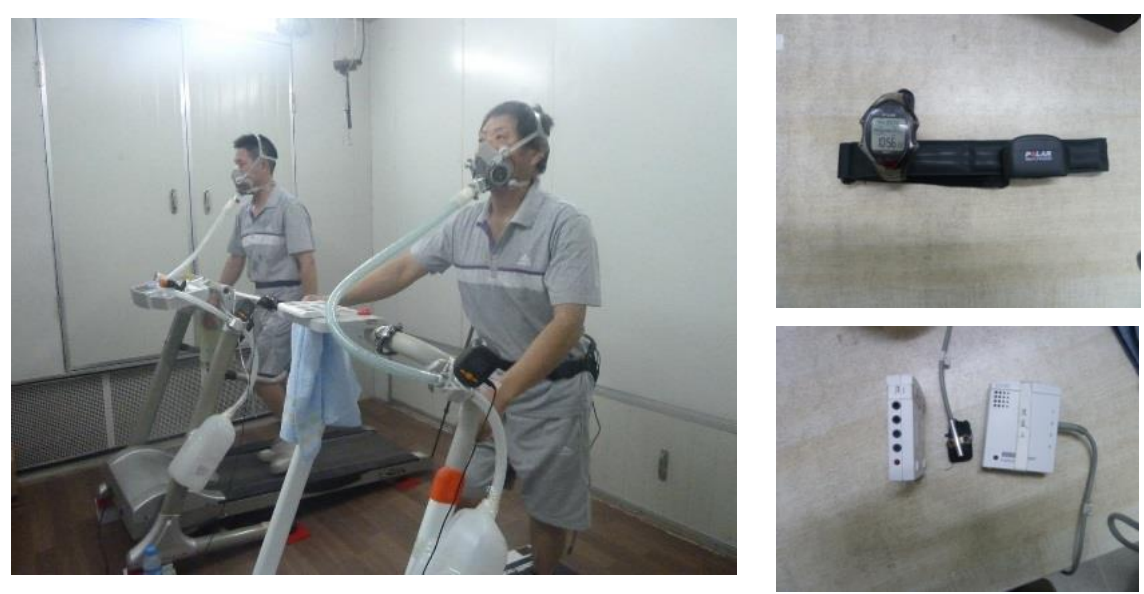

Figure 1 Treadmill exercises during heat exposure experiment

(Note: exhaled air from the subjects was collected during the trials, to measure the oxygen consumption rate and infer metabolic rates of subjects. In this paper, we have omitted the exhaled air data for the sake of simplicity focusing the aims of this study.)

Table 3 Measuring parameters and instrument information

\begin{tabular}{|c|c|c|c|c|c|}
\hline Index & Instrument & Company & Range & Accuracy & Frequency \\
\hline $\begin{array}{l}\text { Local skin } \\
\text { temperature }\end{array}$ & TMC6-HD & $\begin{array}{l}\text { U12-0064, } \\
\text { HOBO,US }\end{array}$ & $-40-100^{\circ} \mathrm{C}$ & $\pm 0.2^{\circ} \mathrm{C}$ & $10 \mathrm{~s}$ \\
\hline $\begin{array}{l}\text { Rectal } \\
\text { temperature }\end{array}$ & TMC6-HD & $\begin{array}{l}\text { U12-0064, } \\
\text { HOBO,US }\end{array}$ & $-40-100^{\circ} \mathrm{C}$ & $\pm 0.2^{\circ} \mathrm{C}$ & $10 \mathrm{~s}$ \\
\hline Heart rate & $\begin{array}{l}\text { Polar } \\
\text { RS800 }\end{array}$ & $\begin{array}{l}\text { Polar, } \\
\text { Finland }\end{array}$ & I & $\pm 3 \mathrm{bpm}$ & $1 \mathrm{~min}$ \\
\hline Sweat loss & $\begin{array}{l}\text { Electronic } \\
\text { weighting }\end{array}$ & ACS, China & I & $\pm 10 \mathrm{~g}$ & I \\
\hline $\begin{array}{l}\text { Thermal } \\
\text { environment }\end{array}$ & $\begin{array}{l}\text { Thermal } \\
\text { comfort } \\
\text { instrument }\end{array}$ & LSI, Italy & $\begin{array}{l}\text { temperature range: - } \\
25-150{ }^{\circ} \mathrm{C} \\
\text { global temperature: - }\end{array}$ & $\begin{array}{l}\text { temperature } \\
\text { accuracy: } \pm 0.1^{\circ} \mathrm{C} \\
\text { global temperature: }\end{array}$ & $10 \mathrm{~min}$ \\
\hline
\end{tabular}




\subsection{Statistics analysis}

The recorded values of Tsk, Tre, SR in 10 subjects were averaged in intervals of 10 min under different experimental conditions (Table 1). We calculated the mean Tsk, Tre and SR for 10-minute intervals to represent the changes of these physiological indices at $\mathrm{t}=0,10,20, \ldots 120 \mathrm{~min}$. The values predicted by the PHS model were calculated at $10 \mathrm{~min}$ intervals following the procedure in Annex E of the ISO 7933 standard[27]. The inputs were based on the experimental designs and basic information from subjects, and the results were compared to experimental data.

First, the two-way analysis of variance (ANOVA) test was used to identify significant differences of the physiological indices among 10 subjects at the initial time, with the experimental conditions as the fixed factor and the individual subject as the random factor. When analysing the effect of temperature and $\mathrm{RH}$ on physiological responses in different experimental conditions, the repeated ANOVA was used, with time as the repeated factor and the conditions as the fixed factor. The StudentNewman-Keuls (S-N-K) method was used for multiple comparisons if the ANOVA analysis revealed significant differences among different conditions. In addition, the regression analysis was employed to examine the relation between the measured physiological indices and the predicted values by the PHS model. Statistical significance was acceptable with $\mathrm{p}<0.05$.

One aim of this research was to assess the agreement of the physiological responses between the values predicted in the PHS model and the results measured in experiments. However, in statistics, widely-used evaluation methods like comparison of means, correlation coefficients, and regressions have been criticized as inappropriate for assessing the agreement between two different measures [45]. Bland et al. [46, 47] proposed a method to assess the agreement between two methods, which is referred to 
as Bland-Altman analysis. Bland-Altman analysis is based on graphical techniques and simple calculations, and it has been verified as giving the most appropriate performance for assessing agreement between two methods [48]. Therefore, we used the BlandAltman method to evaluate the relationship between the observed and predicted results.

Tre, Tsk and SR of subjects were chosen as evaluation indices. The experimental data were grouped by time intervals: $10-40 \mathrm{~min}, 50-80 \mathrm{~min}$, and $90-120 \mathrm{~min}$. The mean differences in these parameters between the PHS model and experiments were then calculated, along with the standard deviations. The degree of agreement, i.e. the limits of agreement ( $\mathrm{d} \pm 2 \mathrm{sd}, 95 \%$ confidence interval $(95 \% \mathrm{CI}))$ were calculated. The differences were defined as (observed values - predicted values) and the mean values were averaged by (observed values + predicted values)/2. To explain here, the degree of agreement between the experiments and the model predictions using Bland-Altman analysis is dependent on "whether the differences provided by the limits of agreement" are acceptable by the users themselves, based on their experience. Therefore, it is dependable. This study assumed that the PHS model is considered acceptable only if the provided differences were within the limits of agreements of 95\%CI. This method was just applied in verification of PHS model; the modification of the PHS model in this study was evaluated by a proposed quantitative index in the following analysis. The principles and details of the Bland-Altman analysis can be referred to Refs.[46, 47].

Both ISO 9886 [49] and the WHO [41] recommend that core temperature during heavy long-term physical labour should not exceed $38{ }^{\circ} \mathrm{C}$. With this prerequisite, the maximum allowable exposure time, as the target output of the PHS model that is used for application to guide human thermal protection in hot environment, is the lesser of the time at which the rectal temperature exceeds $38{ }^{\circ} \mathrm{C}$ and the time at which the water loss exceeds the corresponding proportion of body weight[27]. Therefore, for PHS model modification, the actual exposure time of subjects in the experiments and the the maximum allowable exposure time predicted by the modified PHS model were obtained. To quantitatively evaluate the predicted performance of the modified PHS model, we define the term of protective efficacy (PE) in Equation (1). 


$$
\mathrm{PE}=\frac{\left.\mathrm{S}_{\left(\mathrm{tact}_{\mathrm{c}}<\mathrm{t}\right. \text { pre }}\right)}{\mathrm{S}_{\text {total }}} \times 100 \%
$$

where $S_{\text {total }}$ is the total samples recorded from all subjects and in all experimental conditions; $S_{(\text {tact }<\text { tpre })}$ is the number of samples for which the actual exposure time is lower than the maximum allowable exposure time.

Correspondingly, the over-protection rate (OP-R) was determined as the proportion of samples for which the difference between the actual and predicted exposure time exceeded $30 \%$ of the predicted exposure time. This definition is expressed in Equation (2). This index was provided to compare the prediction performance of the original PHS model and the modified model, considering the PHS model might have the possibility to under-estimate the exposure time after modification.

$$
\mathrm{OP}-\mathrm{R}=\frac{\mathrm{S}_{\left(\left(\left|\mathrm{t}_{\text {act }}-\mathrm{t}_{\text {pre }}\right|\right)>30 \% \mathrm{t}_{\text {pre }}\right)}}{\mathrm{S}_{\text {protection }}} \times 100 \%
$$

where OP-R is the protective efficacy; $\mathrm{S}_{\text {protection }}$ is the samples that subjected have been protected by allowable exposure time; $\mathbf{S}_{(\mid \text {tact-tpre } \mid>30 \% \text { tpre) }}$ is the number of samples foe which the difference between the actual exposure time and the maximum allowable exposure time in PHS model is higher than $30 \%$ of the maximum allowable exposure time.

These two quantitative indices are used in Section 4 to evaluate the performances of the modified PHS model, comparing to the original PHS model.

\section{Verification of the PHS model}

The PHS model provides a method to evaluate human heat strain through predicting rectal temperatures, mean skin temperatures, and sweat rates [27]. In addition, the maximum allowable exposure time is determined when rectal temperature or cumulative water loss reaches limit values [27]. Therefore, this section, as well as the Appendices, mainly analysed the experimental results of Tre, Tsk, SR and the maximum allowable exposure time of subjects to heat exposure, and compared to the predicted values by the PHS model. 


\subsection{Exposure time and corresponding physiological responses}

We monitored Tre and HR from each subject during the tests and recorded the number of subjects who completed 120 min of heat exposure in each experimental condition. Table 4 summarizes how many tests were terminated under each condition. No subjects suspended the test when the RH was $25 \%$, and the number of terminations increased as RH increased from $25 \%$ to $40 \%$ to $60 \%$. Increasing temperature at high humidity encouraged even more subjects to terminate the trials. All subjects quit the experiment before 120 min under the conditions of $38{ }^{\circ} \mathrm{C}$ and $60 \% \mathrm{RH}$ and $40{ }^{\circ} \mathrm{C}$ and $60 \% \mathrm{RH}$, indicating the significant coupling effect of temperature and humidity on comfort. Under these respective conditions, $90 \%$ and $80 \%$ of the subjects had rectal temperature exceeding $39^{\circ} \mathrm{C}$, while no subject was found with $\mathrm{HR}$ higher than $180 \mathrm{bpm}$. In this case, the rectal temperature is a more conservative evaluation indicator for heat strain.

Table 4 Trial terminations

\begin{tabular}{ccccc}
\hline Conditions & Tre $>39^{\circ} \mathrm{C}$ & HR $>180 \mathrm{bpm}$ & Terminations & Completions \\
\hline $\mathrm{A} 1\left(35^{\circ} \mathrm{C} / 25 \%\right)$ & 0 & 0 & 0 & 10 \\
$\mathrm{~A} 2\left(35^{\circ} \mathrm{C} / 40 \%\right)$ & 0 & 0 & 0 & 10 \\
$\mathrm{~A} 3\left(35^{\circ} \mathrm{C} / 60 \%\right)$ & 6 & 0 & 6 & 4 \\
$\mathrm{~B} 1\left(38^{\circ} \mathrm{C} / 25 \%\right)$ & 0 & 0 & 0 & 10 \\
$\mathrm{~B} 2\left(38^{\circ} \mathrm{C} / 40 \%\right)$ & 2 & 0 & 2 & 8 \\
$\mathrm{~B} 3\left(38^{\circ} \mathrm{C} / 60 \%\right)$ & 9 & 0 & 10 & 0 \\
$\mathrm{C} 1\left(40^{\circ} \mathrm{C} / 25 \%\right)$ & 0 & 0 & 0 & 10 \\
$\mathrm{C} 2\left(40^{\circ} \mathrm{C} / 40 \%\right)$ & 5 & 0 & 7 & 3 \\
$\mathrm{C} 3\left(40^{\circ} \mathrm{C} / 60 \%\right)$ & 8 & 0 & 10 & 0 \\
\hline
\end{tabular}

To allow a clear comparison between the predicted safe exposure time in the PHS model and the experimental results, the mean exposure times of 10 subjects walking on the treadmill in 9 conditions are plotted in Figure 2 with a bar graph, along with the corresponding values predicted by the PHS model using the experimental inputs. Overall, both the predicted safe exposure time and the observed termination time 
decreased gradually with increasing temperature and $\mathrm{RH}$, and the effect was more significant at $40{ }^{\circ} \mathrm{C}$ and $60 \% \mathrm{RH}$, for which the safe exposure time was less than 20 min. However, the PHS model overestimated the safe exposure time in all 9 conditions and the differences increased when the temperature and $\mathrm{RH}$ were high. The maximum deviation was $50 \mathrm{~min}$ at $38{ }^{\circ} \mathrm{C}$ and $40 \% \mathrm{RH}$. This finding shows that the PHS is risky to use for predicting safe heat exposure for Chinses workers.

We additionally averaged the terminating Tre and Tsk of subjects in different conditions, and these results are plotted in Figure 2 with solid lines. The predicted Tre and Tsk values are plotted with dotted lines. The PHS model captured the general trends of Tre and Tsk under different heat exposure conditions. However, the terminating Tre and Tsk in experiments were higher than the predicted values in all 9 conditions, which indicates that the PHS model under-estimates subjects' actual safe Tre and Tsk values. Moreover, these deviations increased as the temperature and humidity increased, with the largest value of $0.5{ }^{\circ} \mathrm{C}$ for Tre and Tsk at $38^{\circ} \mathrm{C}$ and $40 \% \mathrm{RH}$. Because the two-way ANOVA found no significant differences in the initial Tre and Tsk among 10 subjects $(\mathrm{p}=0.389)$ and under different experimental conditions $(\mathrm{p}=0.068)$, the differences in Tre and Tsk by the end of experiments could be attributed to changes in the temperature and humidity. Therefore, environmental temperature and relative humidity are significant considerations when workers are exposed to hot environments.

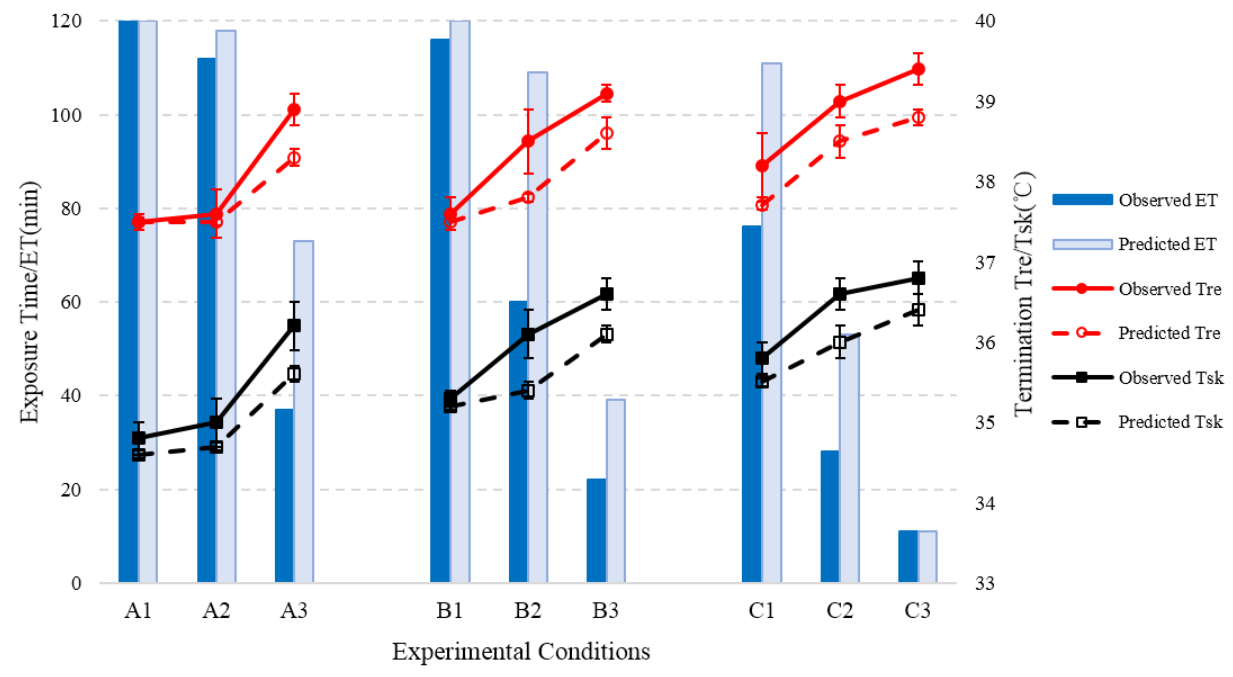


Figure 2 Exposure time and the final values of Tre and Tsk in the 9 conditions

(Note: the blue bars represent the measured exposure time when one of the subjects terminated the tests during heat exposure; the shallow bars represent the predicted allowable exposure time under the same condition; the red lines (solid for experimental results and dot for predicted values using the PHS modle) are the ending mean values of rectal temperatures of 10 subjects under 9 designed conditions and the black ones are the ending values of mean skin temperatures.)

\subsection{Validation of the PHS model predictions}

To examine the prediction performance of the PHS model, the predicted physiological responses of Tre, Tsk and SR were calculated from the experimental inputs. These results are compared to the measured Tre, Tsk and SR for 10 subjects in experiments in Figure 3. Further, we applied a linear regression between the observed and predicted values among the 10 subjects in all 9 conditions, which is plotted with solid red lines in Figure 3. The 95\% confidence interval (CI) for the regression models is plotted with solid blue lines. Significant correlations were found between the values predicted by the PHS model and the observed values, and the regression coefficients were $1.16,1.14$, and 0.84 , respectively. These regression coefficients mean that subjects' actual Tre and Tsk responses were more sensitive to heat stimuli than the PHS model predicted, while subjects in fact sweated less than predicted. Overall, regardless of the 95\% CI, the measured Tre, Tsk and SR values frequently were out of the 95\% CI zone in some cases. These scatters in the regression suggests that the PHS model may raise health risks when applied to Chinese workers. 

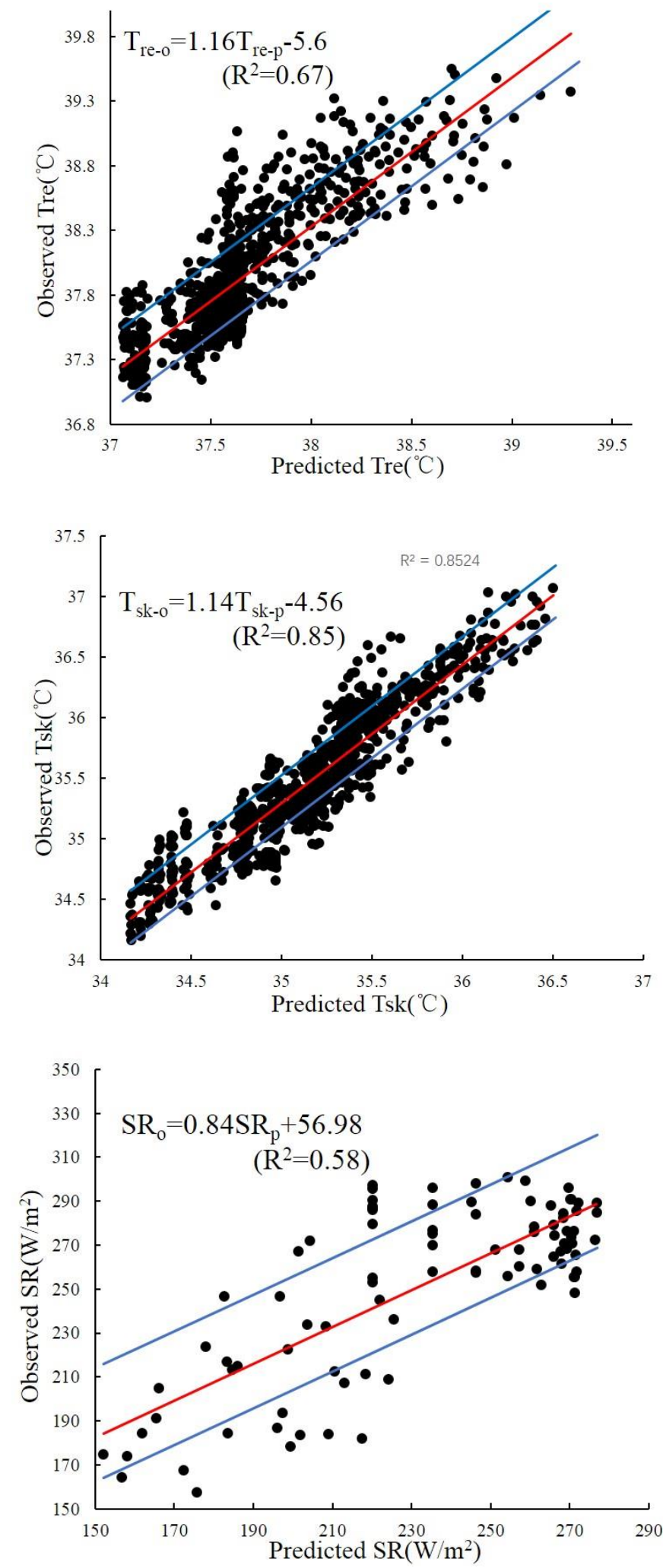

Figure 3 Regression of observed and predicted Tre, Tsk and SR

(note: scatter points are the measured and predicted values for each subject under nine conditions) 
Figure 3 gives a general evaluation of the prediction performance of the PHS model, but this data cannot address the dynamic predictive ability of the model. Considering that heat stress affects core temperature [50], Figure 4 takes the physiological index Tre as an example and plots the changes in the mean Tre values over time (solid lines) under all conditions. The values of Tre predicted by the PHS model are shown with dotted lines in Figure 4. Note that the mean Tre in Figure 4 was calculated before the first of the 10 subjects terminated the test. First, the observed Tre increased remarkably with temperature and the increase was more significant at $60 \%$ RH (red lines). For example, the ending Tre values were lower than $38.5^{\circ} \mathrm{C}$ at $35^{\circ} \mathrm{C}$ and $38{ }^{\circ} \mathrm{C}$ but were higher than $39{ }^{\circ} \mathrm{C}$ at $40{ }^{\circ} \mathrm{C}$. The increment was greater at $60 \% \mathrm{RH}$, when the Tre increased from nearly $37.2{ }^{\circ} \mathrm{C}$ to $39.1{ }^{\circ} \mathrm{C}$ in trial $\mathrm{C} 3\left(40{ }^{\circ} \mathrm{C}\right.$ and $60 \% \mathrm{RH})$. When comparing the 9 conditions, Tre differed significantly under the three different temperature and humidity levels (repeat ANOVA, $\mathrm{p}=0.025$ ). Multiple comparisons of Tre show that when the relative humidity was lower than $40 \%$, Tre was not significantly different between the three temperature levels $(p=0.221,0.120$, 0.290). When the relative humidity was $60 \%$, Tre was significantly higher. As we expected, evaporative heat loss was restrained due to the higher water-vapour pressure at higher humidity, resulting in increased heat storage in the body and thus increased Tre.

Further comparing the observations and predictions, in moderately hot environments (e.g., A1 $\left.\left(35^{\circ} \mathrm{C} / 25 \% \mathrm{RH}\right), \mathrm{A} 2\left(35^{\circ} \mathrm{C} / 40 \% \mathrm{RH}\right), \mathrm{B} 1\left(38{ }^{\circ} \mathrm{C} / 25 \% \mathrm{RH}\right)\right)$, the PHS model predicted subjects' Tre well. The ending Tre stabilized around 37.6-37.8 ${ }^{\circ} \mathrm{C}$. In contrast, with increasing temperature and $\mathrm{RH}$, the predicted and observed Tre values of subjects increased following similar trends and continued to increase after the tests were terminated. However, the differences between the values increased. For example, when RH was $60 \%$, the real Tre values were much higher than the predicted ones; with deviations up to $0.7{ }^{\circ} \mathrm{C}$ at $35^{\circ} \mathrm{C} / 60 \% \mathrm{RH}$. At $40^{\circ} \mathrm{C}$, the predicted and actual values were significantly different at low $\mathrm{RH}\left(40{ }^{\circ} \mathrm{C} / 25 \% \mathrm{RH}\right)$. These differences indicate that the 
higher temperature and RH conditions increased heat strain on the body. In this case, the PHS model significantly under-predicted the inner core temperatures of Chinese workers, which responds to the changes of exposure time in Figure 2.
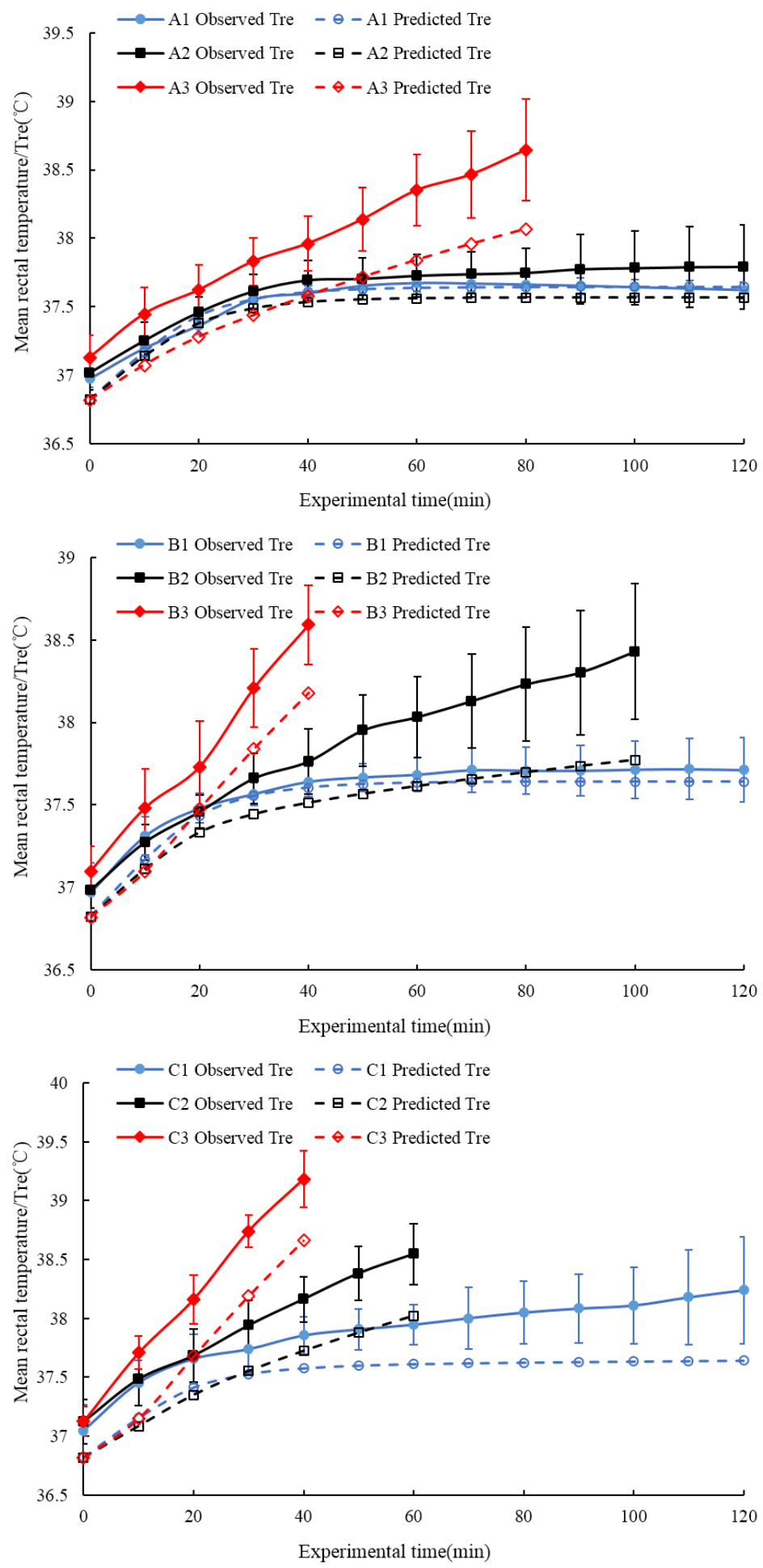

Figure 4 Comparison between the measured and predicted Tre in PHS model 
(Note: similar trends appear in the Tsk values, and the analyses are provided for reference in

Appendix A.)

\subsection{Bland-Altman analysis of the PHS model}

We employed Bland-Altman analysis to verify the deviations between the PHS model and the experimental data. The method was introduced in Section 2.4 and the results are presented in this section.

\subsubsection{Tre verification}

Figure 5 plots the absolute differences between the observed Tre $\left(\operatorname{Tre}_{\mathrm{o}}\right)$ and predicted Tre (Tre $\mathrm{p}_{\mathrm{p}}$ ) values against their mean values within three periods (10-40 min, 50-80 min, 90-120 min). The grey lines in Figure 5 plot the zero baseline and the black solid lines are the means of the differences between $\mathrm{Tre}_{\mathrm{o}}$ and $\mathrm{Tre}_{\mathrm{p}}$. The distance between the black line and the zero line in each graph reflects the systematic error between the actual measured values and the predicted values. The grey dotted lines are the 95\% CI for the differences between the measured and the predicted values, and random error is apparent. When random error does not affect the results, the predicted values and the measured values can be regarded as consistent, while significant effects indicate inconsistency such that the predicted values cannot be used to represent the measured ones.

Tre $_{\mathrm{p}}$ agreed significantly with $\mathrm{Tre}_{\mathrm{o}}$ under conditions A1, A2 and B1, which is consistent with the dynamic changes of Tre shown in Figure 4. The mean values of the differences between the observed $\mathrm{Tre}_{\mathrm{o}}$ and the predicted $\mathrm{Tre}_{\mathrm{p}}$ were nearly equal to 0 (black lines in Figure 5), indicating that no systematic error affected the results. With increasing temperature and relative humidity, the mean values of the differences increased gradually, so the systematic error caused by the predictions of the PHS model increased. The difference reached $0.52{ }^{\circ} \mathrm{C}$ in the $\mathrm{C} 3$ trials. Similarly, Figure 5 shows that the $95 \% \mathrm{CI}$ of the differences increased with increasing temperature and $\mathrm{RH}$. The difference was 0.36 under $\mathrm{A} 1$ and increased to 1.13 under $\mathrm{C} 1$. This change is related to the deviant predictions of the PHS model in hot environments, and is in agreement with 
the changes shown in Figure 4 and Appendices A.1 and A.2. Further analysis of Figure 5 shows that the exposure time during different periods, shown in different colours, also impacts the relationship between the predicted and observed Tre values. The differences $\left(\mathrm{Tre}_{\mathrm{o}}-\mathrm{Tre}_{\mathrm{p}}\right.$ ) were bigger during the period 50-80 min (red circle), especially under A3, $\mathrm{B} 2$, and $\mathrm{C} 2$, for which the distribution of differences are more discrete. Close attention to Figure 5 shows that more values were distributed outside the $95 \%$ CI when the measured mean Tre of the subjects exceeded $37.8{ }^{\circ} \mathrm{C}$. This spread indicates that the prediction performance of the PHS model in hot environments is unacceptable and more attention should be paid to the application of the PHS model under such conditions.
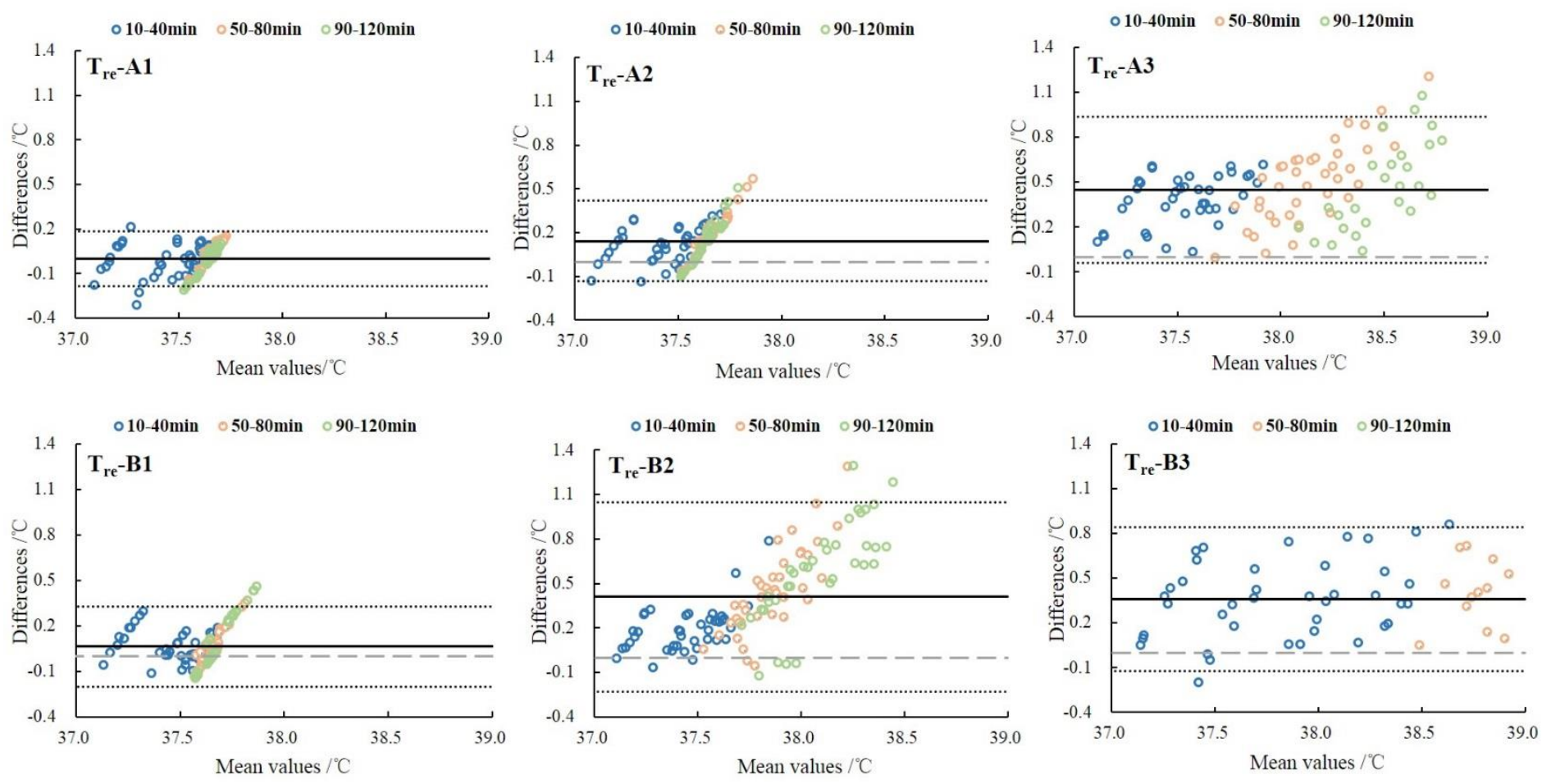

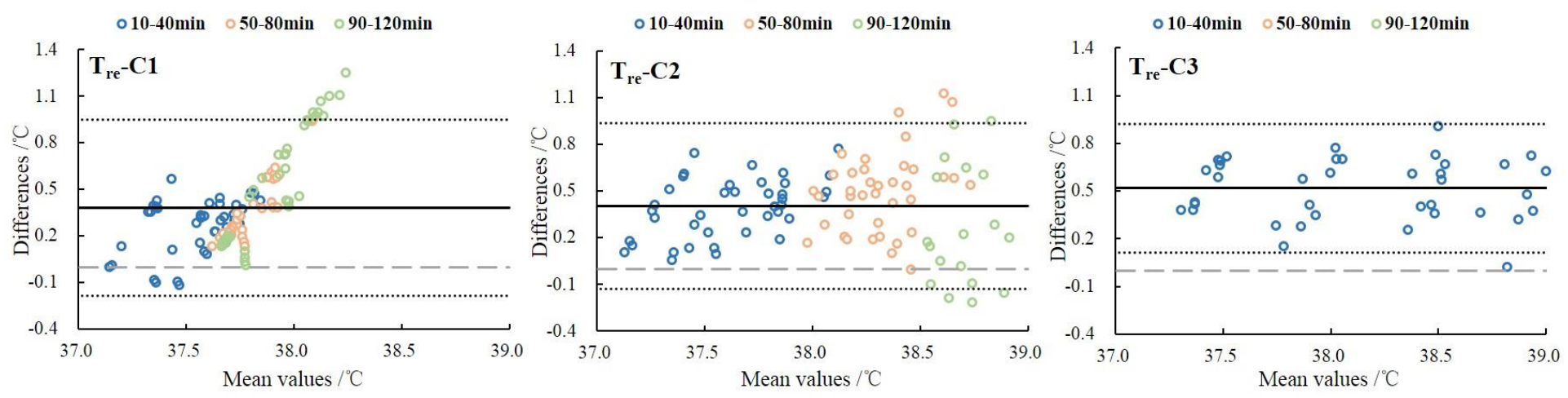

Figure 5 Bland-Altman analysis of Tre

Note: The differences in the Y-Axis is defined as $\left(\operatorname{Tre}_{\mathrm{o}}-\operatorname{Tre}_{\mathrm{p}}\right)$ and the mean value in the X-Axis is defined as $\left(\operatorname{Tre}_{\mathrm{o}}+\operatorname{Tre}_{\mathrm{p}}\right) / 2$

In a similar vein, Bland-Altman analysis was conducted to compare the differences between the predicted and the measured Tsk. The results are presented for reference in Appendix B.1. The trends of Tsk are similar to that of Tre, suggesting that the skin temperatures are affected by core temperature during heat exposure.

\subsubsection{SR verification}

The body-weight loss of each subject during the trials was measured and was transformed into joules by adopting the vaporization heat of $2413 \mathrm{~J} / \mathrm{g}\left(37^{\circ} \mathrm{C} / 50 \% \mathrm{RH}\right)$. The SR was then defined as the latent heat transfer per unit area at the skin surface of subjects. Figure 6 presents the differences between the predicted and the observed SR of 10 subjects under all 9 conditions. As seen in Figure 6, the predicted SRs of subjects in the PHS model were higher than the values measured in experiments, the mean value difference being $-33.3 \mathrm{~W} / \mathrm{m}^{2}$ (solid line). The lower limit of the $95 \% \mathrm{CI}$ is $-80.5 \mathrm{~W} / \mathrm{m}^{2}$ and the upper limit is $+17.8 \mathrm{~W} / \mathrm{m}^{2}$ in Figure 6 . These limits indicate that the PHS model overestimates sweating regulation for these Chinese workers, which is consistent to SR changes in Appendix A.2. However, Figure 6 demonstrates that most of values were within the $95 \%$ CI zone. When the mean value exceeded $230 \mathrm{~W} / \mathrm{m}^{2}$, the distribution of differences between the predicted and measured SR values was more uniform. 


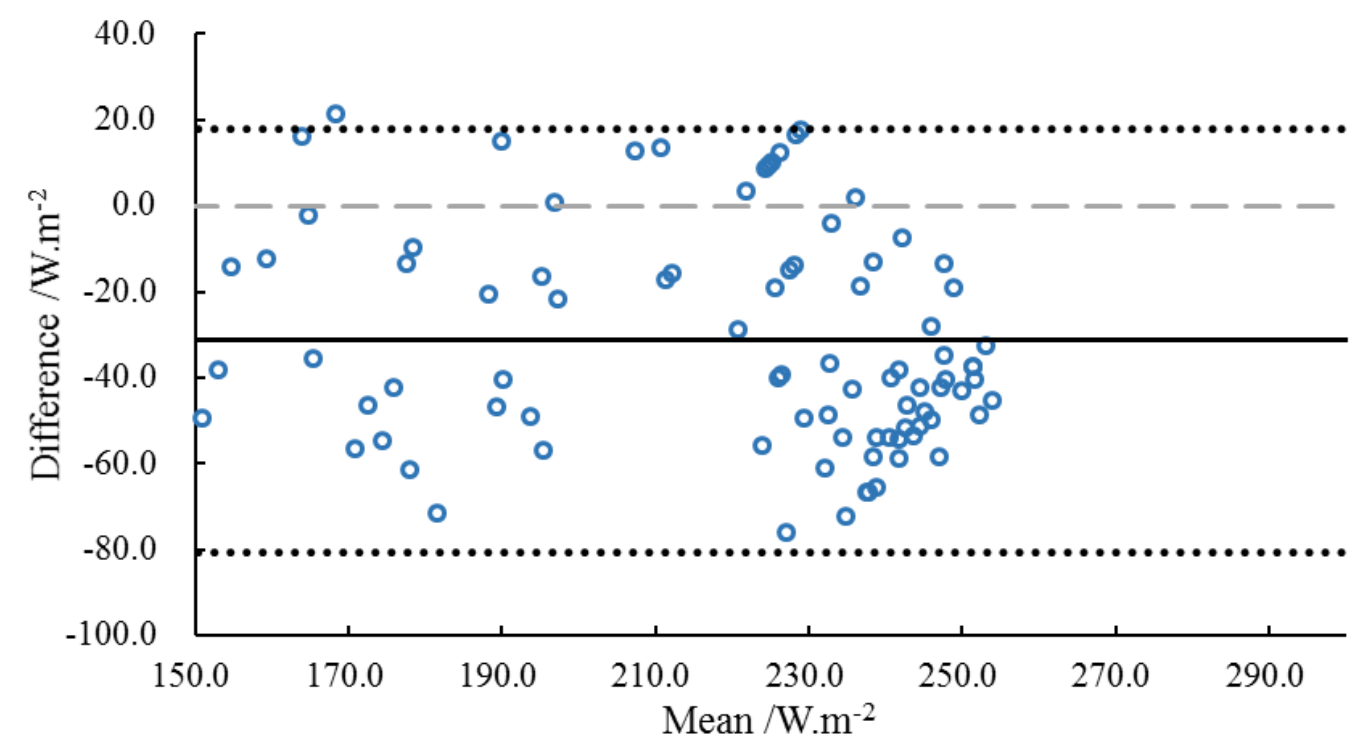

Figure 6 Bland-Altman analysis of SR

(Note: Difference values in the Y-Axis are defined as $\left(\mathrm{SR}_{\mathrm{o}}-\mathrm{SR}_{\mathrm{p}}\right)$ and the mean value in the $\mathrm{X}$ -

Axis is defined as $\left.\left(\mathrm{SR}_{\mathrm{o}}+\mathrm{SR}_{\mathrm{p}}\right) / 2\right)$

\section{Modification of the PHS model}

Because the PHS model was established for an average European population, the model inputs likely differ, such as the variability of thermal regulation with age, genetic differences, physical differences, heat acclimation, and living habits for Chinese populations. The above results by Figures 2-6 show that the PHS model is ineffective for predicting the physiological responses of Chinese workers in hot environments. However, the verifications above are focused on intermediate variables of Tre, Tsk, SR in the PHS computing program, and the output of the maximum allowable exposure time. To address the prediction deviations of the PHS model, this section focused on analysing the inputs and limits of the PHS model, in order to modification. To evaluate the performance of modification, the output of the maximum allowable exposure time in the PHS model was mainly considered as target. The protective efficacy index proposed in Section 2.4 is deployed, to evaluate the changes of allowable exposure time between the original and the modified PHS model.

To achieve this aim, we here modified the PHS model through fine-tuning the 
inputs of the model in three ways: adjusting the initial Tre, adjusting the maximum HR, and modifying the real metabolic rates, considering the characteristics of Chinese workers and the convenient application in reality. Details are given to elaborate the methods in the following parts.

\subsection{Protective efficacy(PE) of the current PHS model}

First, Figure 7 plots a comparison of actual exposure time in all experiments and the predicted maximum allowable exposure time; the black line represents the observed values being equal to the predicted values. Most of the values are distributed to the left side of the $\mathrm{Y}=\mathrm{X}$ line, indicating that the predicted allowable exposure times for the subjects were obviously higher than the actual times measured in experiments. The PE of the PHS model was calculated using Equations (1) and (2) in Section 2.4. The results show that only $24.7 \%$ of the subjects are protected by the exposure time recommended by the PHS model and the OP-R was 0\%. This indicates that the original PHS model overestimates the maximum allowable exposure time for Chinese subjects.

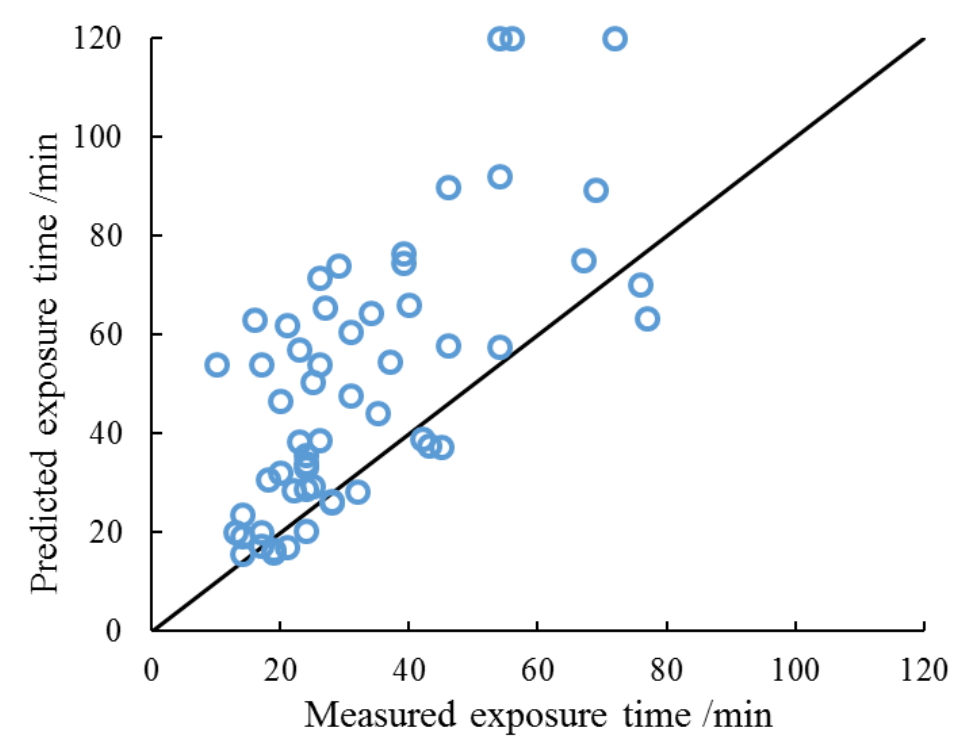

Figure 7 Comparison of exposure time between observed and predicted values 


\subsection{Tre adjustment}

Figure 7 addressed that the current PHS model has weaker protection efficacy for Chinese workers in hot environments. In the PHS model, the Tre at the start of the trial is set to $36.8{ }^{\circ} \mathrm{C}$, which is adopted as the default starting value. In contrast, the initial Tre as measured in our experiments is shown in Table 5 and the averaged value under all conditions is $37.0^{\circ} \mathrm{C}$. Nonparametric testing shows that the initial Tre values were normal (K-S test, $\mathrm{p}=0.244)$ under all 9 conditions, and that the initial Tre values and the default value of $36.8{ }^{\circ} \mathrm{C}$ in the PHS model were significantly different (t test, $\mathrm{p}=0.004)$.

Table 5 Mean and SD of initial Tre

\begin{tabular}{cccc}
\hline No & Conditions & Means & SD \\
\hline A1 & $35^{\circ} \mathrm{C} / 25 \%$ & 37.0 & 0.10 \\
A2 & $35^{\circ} \mathrm{C} / 40 \%$ & 37.0 & 0.13 \\
$\mathrm{~A} 3$ & $35^{\circ} \mathrm{C} / 60 \%$ & 37.1 & 0.17 \\
$\mathrm{~B} 1$ & $38^{\circ} \mathrm{C} / 25 \%$ & 37.0 & 0.18 \\
$\mathrm{~B} 2$ & $38^{\circ} \mathrm{C} / 40 \%$ & 37.0 & 0.11 \\
$\mathrm{~B} 3$ & $38^{\circ} \mathrm{C} / 60 \%$ & 37.1 & 0.15 \\
$\mathrm{C} 1$ & $40^{\circ} \mathrm{C} / 25 \%$ & 37.0 & 0.22 \\
$\mathrm{C} 2$ & $40^{\circ} \mathrm{C} / 40 \%$ & 37.1 & 0.19 \\
$\mathrm{C} 3$ & $40^{\circ} \mathrm{C} / 60 \%$ & 37.1 & 0.12 \\
\hline
\end{tabular}

Therefore, based on experimental data, we first attempt to raise the default Tre to $37.0^{\circ} \mathrm{C}$ in the PHS model. The maximum allowable exposure times from the modified PHS model are thus calculated. Figure 8 shows the predicted results from raising the initial Tre to $37.0{ }^{\circ} \mathrm{C}$. Compared to Figure 7 , more points close to the $\mathrm{Y}=\mathrm{X}$ line, suggesting that the predicted allowable exposure time is shortened. The calculated PE is improved to $57.1 \%$ in Figure 8, which is a $35.7 \%$ improvement over the original PE. The obtained OP-R is $21.9 \%$. The results reveal that the default value of $36.8{ }^{\circ} \mathrm{C}$ for Tre is relatively conservative so that increasing the initial Tre to $37{ }^{\circ} \mathrm{C}$ improves predictive performance. 


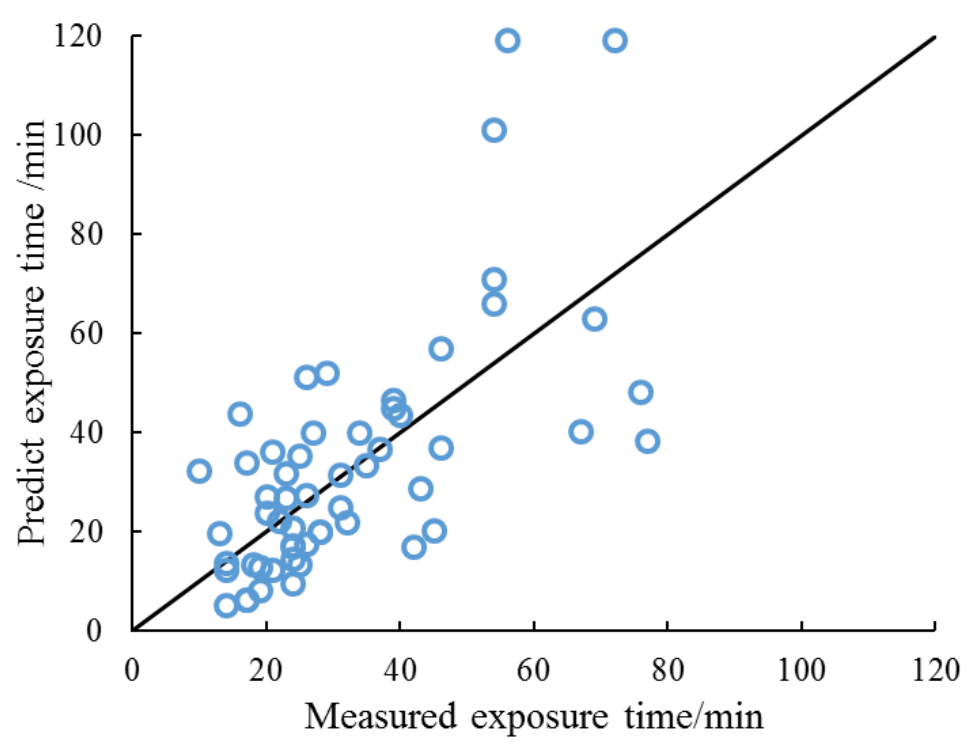

Figure 8 Comparison of exposure times between observed and predicted values of the PHS model with modified initial Tre

\subsection{Maximum HR adjustment}

Heart rate during working is not at a stable level but slowly increases when a person is exposed to a hot environment over time, and the HR may exceed normal limits in extremely hot conditions. Thus, we propose to adjust the maximum HR limits in the PHS model according to individual characteristics. Table 6 summarizes several common methods used for calculating the maximum healthy HR. Among them, the HR percentage method (grey mark in Table 6) is primarily used in professional medical research and is suitable for the age range of 15-65. During continuous labour, the allowable HR using this method should be reduced by $20 \mathrm{bpm}$ to ensure safety. Moreover, this method considers the age factor to evaluate affordances for responding to heat stress, which expands the protection range to cover outlier samples. Therefore, this method is considered as an acceptable way to modify the HR input to improve the PHS model.

Table 6 Calculation methods for maximum safe HR[51, 52, 53]

Methods

Heart rate percentage method
Calculation

$180-0.65 *$ age 
Age subtraction method

Cooper optimum heart rate method

Karvonen exercise heart rate method

Carlson heart rate measurement method

Recommend heart rate reserve method by American

College of Sports Medicine(ACSM)

J Karvonen heart rate reserve method (Finland) 180-age

$(\mathrm{MHR}-\mathrm{RHR}) * 70 \%+\mathrm{RHR}$

(AMHR-RHR)*60\%+RHR

(MHR-RHR)/2-RHR

220-age-RHR

RHR/(MHR-RHR)*60\%

Note: MHR is the maximum heart rate, RHR is the resting heart rate, AMHR is the age-predicted maximum heart rate.

Figure 8 demonstrates adjusting initial Tre in the PHS model. On this basis, we further adjust the maximum HR input in the PHS model using equation in Table 6. Figure 9 shows a comparison of allowable exposure time between the measured results from experiments and the predicted values with modified initial Tre and maximum HR. Similar to Figure 8, the values of predicted allowable exposure time are modified to be close to experimental results after adjusting the maximum $\mathrm{HR}$ in the calculation procedure of the PHS model. The actual PE increases to $71.2 \%$ using the combination of initial Tre and maximum HR adjustment, with an OP-R of $26.8 \%$. This confirms that the PE cab be improved significantly by adjusting the maximum HR and Tre inputs in the PHS model. More importantly, in Figure 7, there were some scatter points that were distributed away from the whole distribution; and in Figure 8 using initial Tre adjustment has less improvement for these specific outliers. By contrast, Figure 9 shows that the adjustment of the maximum HR brings these outliers close to the $\mathrm{Y}=\mathrm{X}$ line. This indicates that introducing the maximum HR adjustment improves the protection efficacy for specific populations whose' heart rates are at high risk during labour. 


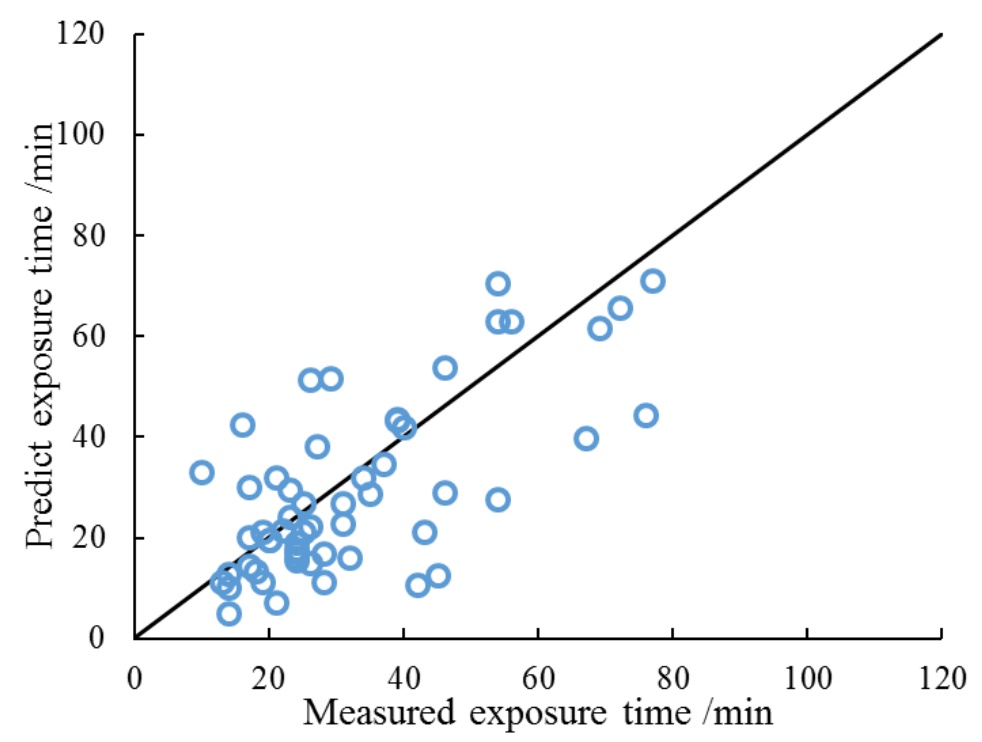

Figure 9 Comparison of exposure time between the observed and predicted values with maximum HR adjustment

\subsection{Metabolic rate prediction based on HR}

Figure 10 shows changes to subjects' mean heart rates with exposure time, differing in different temperature and humidity conditions. From Figure 10, though subjects were walking on the treadmill at a certain speed and the initial HR were close to each other within nine conditions, the mean HR increased gradually with increasing exposure time. The higher the temperature and relativity humidity they were exposed to were, the bigger the differences of the beginning and ending HR. For example, the difference was $35 \mathrm{bpm}$ under A1 while it was up to 58bm under $\mathrm{C} 1$. This indicates that the metabolic rates of subjects will increase continuously over time in hot environments. However, the input metabolic rates in the current PHS model are mostly based on estimated values that overlook the cumulative effects of heat in body. 


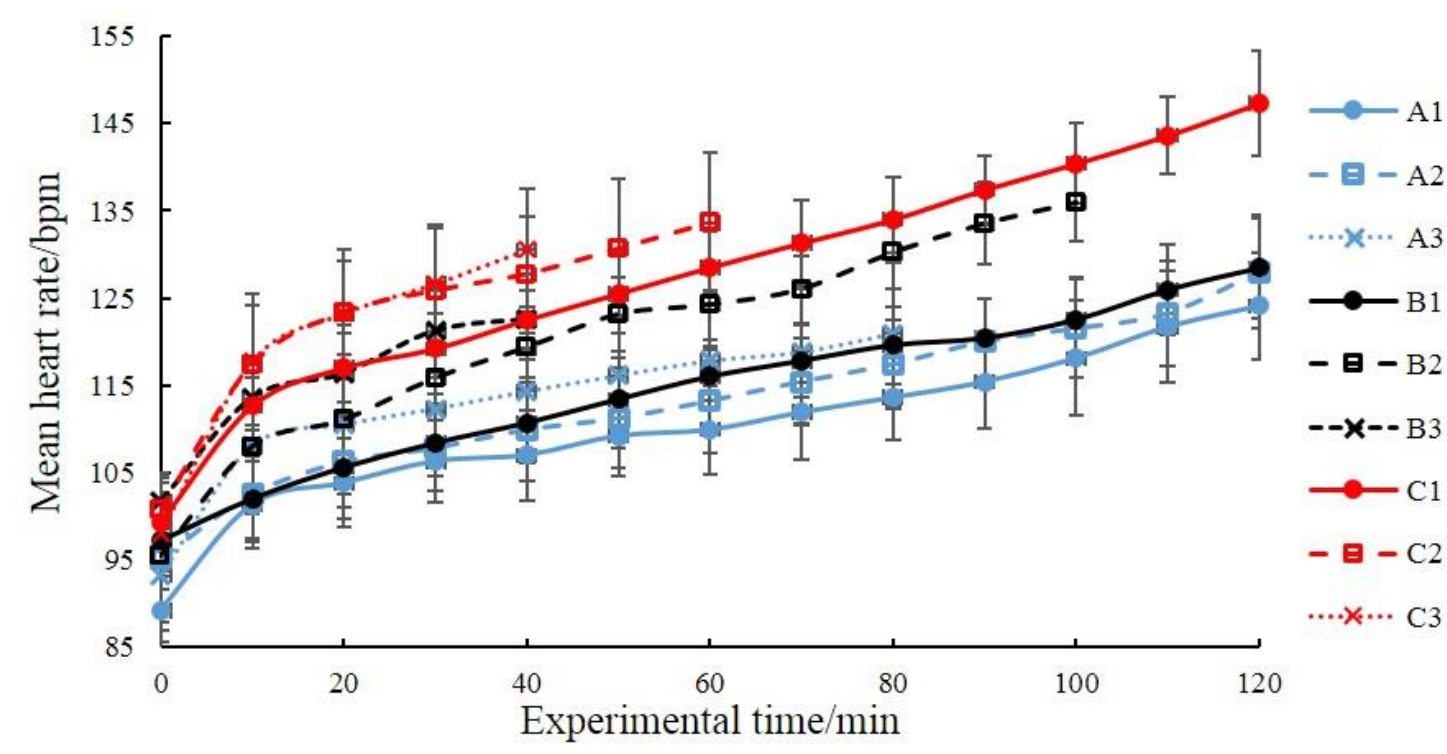

Figure 10 Changes in mean heart rates with time under different conditions

Oxygen consumption measurement is a good method for predicting human metabolic rates with high accuracy (deviation less than 5\%) [54]. However, the testing procedure and instrument for recording oxygen consumption are complex and impractical for monitoring real labour. Therefore, a convenient and accurate method $\mathrm{t}$ for estimating actual activity levels in practical conditions is required.

ISO 8996 [34] provides a linear relationship between HR and metabolic rate, as shown in Equation (3). We can therefore introduce the HR as an indicator to predict the actual metabolic rate, thanks to the continuous monitoring of HR during experiments.

$$
\mathrm{HR}=\mathrm{HR}_{0}+\mathrm{RM} \times\left(\mathrm{M}-\mathrm{M}_{0}\right)
$$

Where $\mathrm{M}$ is the real metabolic rate, $\mathrm{W} / \mathrm{m}^{2} ; \mathrm{M}_{0}$ is the resting metabolic rate, $\mathrm{W} / \mathrm{m}^{2}$, typically defined as $55 \mathrm{~W} / \mathrm{m}^{2}$ when unknown; RM is the slope coefficient for the relationship between the HR and metabolic rate; $\mathrm{HR}$ is the heart rate during activity, bpm; $\mathrm{HR}_{0}$ is the resting heart rate, bpm, typically defined as $65 \mathrm{bpm}$ when unknown.

The slope coefficient RM is calculated as follows.

1) Maximum physical activity for males:

$$
\mathrm{MWC}=(41.7-0.22 \mathrm{~A}) \times \mathrm{W}^{0.666}
$$

where MWC is the metabolic rate, $\mathrm{W} / \mathrm{m}^{2}$; $\mathrm{A}$ is the age, year; $\mathrm{W}$ is the body weight, $\mathrm{kg}$. 
2) Individual maximum allowable HR:

$$
\mathrm{HR}_{\max }=180-0.65 \mathrm{~A}
$$

where $\mathrm{HR}_{\max }$ is the maximum heart rate based on age, bpm; $\mathrm{A}$ is the age.

Here we adopt the HR percentage method from Table 6, which was confirmed with applicable to individuals in the PHS model in Figure 9, instead of the equation in ISO 8996. Thus the slope coefficient of the relationship between HR and metabolic rate can be redefined as in Equation (6).

$$
\mathrm{RM}=\left(\mathrm{HR}_{\max }-\mathrm{HR}_{0}\right) /\left(\mathrm{MWC}-\mathrm{M}_{0}\right)
$$

Owing to the real-time measurement of subjects' HR, the actual metabolic rates are calculated using the above-mentioned method. Recalling Figure 9, when adjusting the maximum HR in the PHS model, the OP-R is higher $(26.1 \%)$, regardless of the higher PE (71.2\%). Therefore, we here use the initial Tre adjustment and modify the metabolic rate input in the PHS model, using real time HR data. The results are demonstrated in Figure 11. Compared to Figure 8, the PE of the modified PHS model is improved from $57.1 \%$ to $68.2 \%$ with OP-R of $25.7 \%$ when using the predicted metabolic rate based on real-time HR. Compared to the combination of adjusting both initial Tre and maximum HR (Figure 9), adjusting initial Tre and adopting the real-time HR for estimating the metabolic rate reduces the PE slightly by $3 \%$. However, in practical workplaces, HR can be measured easily and conveniently with some wearable instruments. Therefore, improving the prediction performance of the PHS model through measuring real-time heart rate is most useful. 


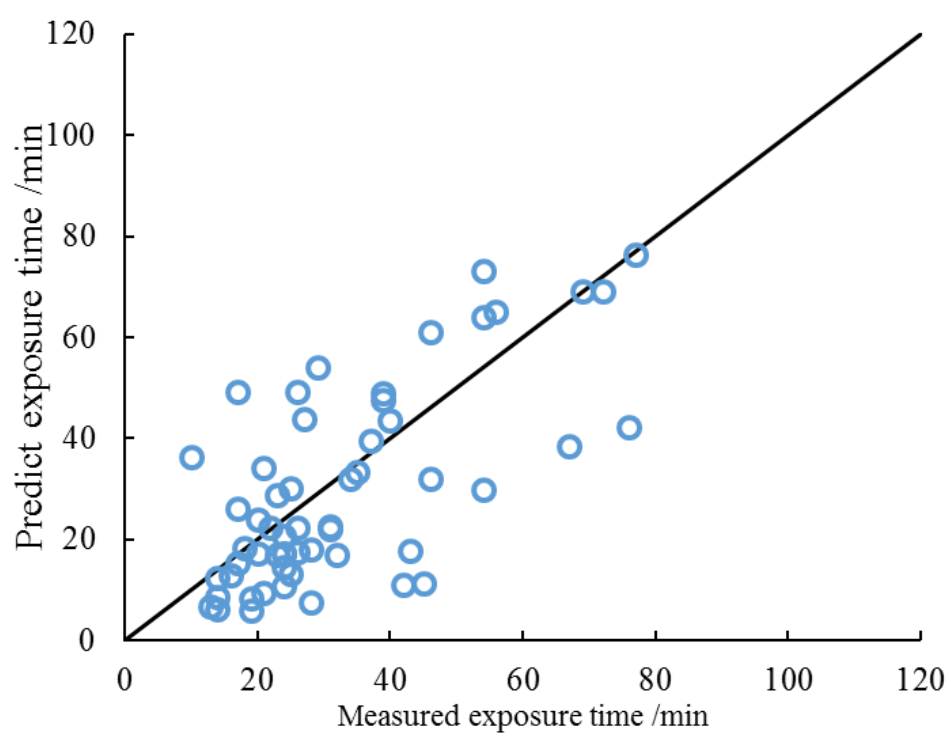

Figure 11 Comparison of exposure time between the measured data and the calculated values based on HR in the PHS model

\section{Discussion and limitations}

We performed heat exposure experiments to examine the application of the PHS model to Chinese workers. Then we developed the model based on theoretical analysis of the calculation steps and proposed three approaches for improving the prediction performance of the current PHS model for Chinese workers. The combined modifications of the PHS model is charted in Figure 12. The flow path in Figure 12 begins with adjusting the initial rectal temperature to $37{ }^{\circ} \mathrm{C}$ according to experimental data and ends with predicting the metabolic rates dynamically using real-time heart rate data. Note that the performance of combining all the three methods (i.e., initial Tre, maximum HR and real-time HR) were not conducted; thus the process of max heart rate adjustment and metabolic rate estimation in Figure 12 is marked with dot lines, which would be further explored. 


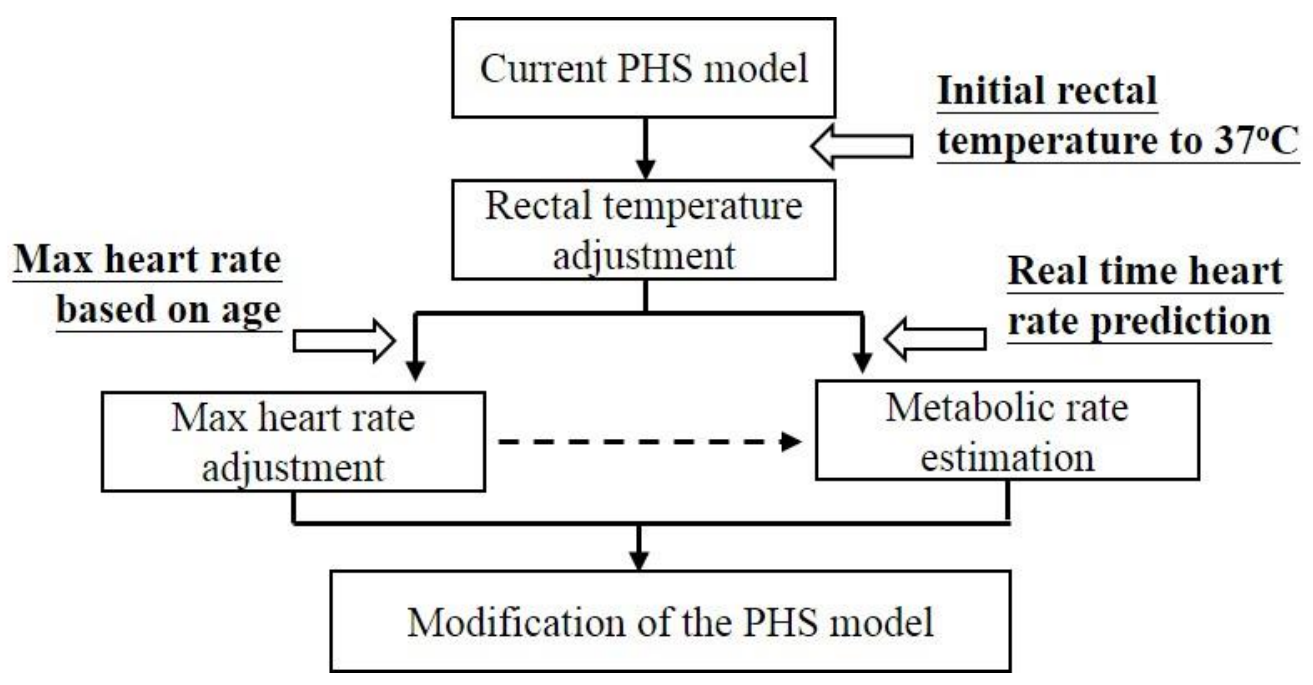

Figure 12 Flow path of the improved PHS model

Because the PHS model is based on an iterative process of calculating the thermal equilibrium between the human and ambient environment at times $\mathrm{t}=\mathrm{t}_{\mathrm{i}}$ and $\mathrm{t}=\mathrm{t}_{\mathrm{i}-1}$, adjusting the initial Tre to $37.0{ }^{\circ} \mathrm{C}$ will shorten the calculation time needed to reach stabilization without affecting the heat equilibrium for certain thermal environments and predicted allowable exposure times. In this case, the modified method in Figure 8 appears reasonable. However, its limitations should be considered. As suggested by the WHO [41] and in ISO 9886[49], the core temperature under non-continuous monitoring should not exceed $38{ }^{\circ} \mathrm{C}$. If this limitation is adhered to, workers experiencing heat illness will be at negligible risk of heat illness [55]. Therefore, if the final Tre is below $38{ }^{\circ} \mathrm{C}$ when using the modified method, improvement of the initial Tre would not affect the predicted allowable exposure time; whereas if Tre exceeds $38{ }^{\circ} \mathrm{C}$ during heat exposure, the time needed for Tre to reach $38^{\circ} \mathrm{C}$ would be regarded as the allowable exposure time. As a result, increasing the initial Tre input will shorten the allowable exposure time. Therefore, this method of adjusting Tre in the PHS model is recommended to apply with certain exclusions and limitations.

To date, the PHS model is one of the most-accurate rational models for predicting physiological heat balance in humans. However, the practicality and applicability of the PHS model in the workplace remain questionable due to the complex parameters to be 
measured and other inputs in the PHS model, which thwart its wider application[56]. For example, some physiological parameters, like core temperature, are difficult to measure without disturbing workers' activities. In addition, the work intensities and the metabolic rates of workers during heat exposure varies with time, leading to prediction deviations in the PHS model[57]. Heart rate has been argued to be closely related to exposure time and work intensity [58], which would affect the cumulative strain and thermoregulatory loads under exercise[52]. We have proposed a method that uses realtime HR to predict the actual metabolic rates of subjects during exercise, instead of the estimation of metabolic rates according to ISO 8996[34]. The protective efficacy was improved from $57.1 \%$ (Figure 8 ) to $68.2 \%$ (Figure 11), based on the modified PHS model. In one of our previous study, Yao et al. [57] mainly focused on real-time HR and improved the theoretical model using real time HR as input in the PHS model; the modified PHS $_{\mathrm{HR}}$ was verified with good prediction performance in dynamic thermal environments, through a simulated heat stress experiment in a chamber, which responds to the method of using real time HR in our study. Therefore, the heart rate can be used as an accurate and practical indicator for heat stress assessment and over-heating protection for workers.

The proposed method in the current study encourages the convenient application of the PHS model in practice. The availability of large amounts of time-series data from wearable devices and systems has enabled the development of physiological models and possess certain characteristics for applications in practical conditions. However, challenges remain in the current heat exposure researches and prediction performance improvement of the physiological PHS model. Skin temperature provides some information about body heat strain, but measuring it requires sensors to be placed on skin surface. As subjects sweat in hot environments, surface sensors must be adhered strongly to skin, to avoid displacement due to sweat and movement that may mislead the measurement [59]. We indeed found during our experiments that the thermocouples tended to loosen or even drop off when the skin surface were wet. Another consideration is that the heat loss by evaporation may decrease the temperature at skin 
surface, so surface the thermocouples may give inaccurate readings. In addition, though rectal temperature is a good index to reflect the core temperature in body, there are no currently convenient instrument and method to monitor the rectal temperature without interrupting workers' activities. Therefore, limitations regarding the measurement instruments and accuracy should be considered for further developments. In contrast, owing to the development of the portable and wireless HR sensors, and more convenient physiological monitoring devices [60, 61], real-time HR data can be recorded easily and monitored without influencing the normal work. This enables the application of PHS model in working places, and the management of prevention and control strategies for occupational health. Certainly, the modified PHS model with realtime HR data should be examined with larger sample sizes and in different situations.

The PHS model, based on human maximum core temperature and maximum sweat loss, has provided a mature theoretical foundation for safety exposure time prediction and is widely accepted for heat strain protection. However, because of the complex factors such as regional climatic characteristics, physiological differences, diet constitution, socio-cultural factors, working environment, psychological effects and other factors, Figure 3 reveals that the PHS model over-predicts the SR of workers in hot environments. On the one hand, the accuracy of the scale used to weight subjects is slightly low ( $\pm 10 \mathrm{~g})$, which may explain some of this deviation. On the other hand, though measuring mass loss during heat exposure is a useful measure of sweat loss, when the body is under heat stress, some sweat will evaporate from unclothed skin, some will be trapped in clothes, and some may remain on the skin surface without evaporating completely. However, the PHS model assumes by default that all sweat evaporates from the skin, which is not the case in reality. This assumption may cause deviations between the measured and the predicted SR. Moreover, in fact, subjective thermal experience and heat acclimatization are beneficial for adapting to hot environments and improving the body's heat tolerance [62]. In this study, all subjects from labour work sector have more than 10 years' experience of physical labour and have formed some degree of thermal adaptations to hot environments. Therefore, they 
seem to tolerate heat exposure before they feel the need to regulate body sweating, which is consistent with some studies [63, 64]. In contrast, the PHS model considers heat acclimatization only for limited physiological parameters (e.g., allowable maximum sweat loss, allowable maximum dehydration). Based on the body's heat balance, physiological adaptation is difficult to be quantified in the equations of the PHS model. Adaptive behaviours are also difficult to include in the theoretical PHS model. Therefore, the PHS model should be developed and improved for various situations, to provide a direct reference and theoretical basis for regional labour-safety regulations and legislation in the future.

\section{Conclusions}

This study examined the performance of the PHS model for predicting the physiological responses of Chinese workers in hot environments and proposed a method to improve the prediction by modifying the inputs. The main results can be summarized as follows:

1) The allowable exposure time decreased gradually as temperature and RH increased in both the predicted PHS model and observations. The PHS model tended to overpredict the exposure time and under-predict the terminating Tre and Tsk, indicating that the PHS model is risky for predicting heat strain in Chinses workers.

2) The experimental results and the values of Tre, Tsk, SR predicted by the PHS model were linearly correlated, with coefficients of 1.16, 1.14 and 0.84 respectively. The measured Tre and Tsk were higher than the predicted values and increased significantly over time, especially in conditions of high temperature and humidity.

3) Bland-Altman analysis verified the significant differences in the predicted and measured values of Tre, Tsk, and SR. The deviations increased with temperature, relative humidity, and exposure time. These trends are attributed to cumulative heat generation and storage in the body after long-term exposure.

4) The protective efficacy of the PHS model was improved from $21.4 \%$ to $57.1 \%$ by 
adjusting the initial Tre to $37{ }^{\circ} \mathrm{C}$. PE was further improved to $71.2 \%$ by adjusting the maximum HR and to $68.2 \%$ when using the real-time heart rate to accurately estimate metabolic rate. These justifications contribute to a convenient modification of the PHS model for Chinese workers and to model applications and over-heating protection in practical hot working environments.

\section{Acknowledgement}

This work was supported by the National Key R\&D Program of China (Grant No: 2016YFC0700300), the Natural Science Foundation of China (Grant No: NSFC 51561135002) and the China Fundamental Research Funds for the Central Universities (Grant No: 2018CDJDCH0015). The authors thank very much for the subjects' participation in the experiments.

\section{References}

[1] IPCC, Fifth Assessment Report on Climate Change, Intergovernmental Panel on Climate Change, World Meteorological Organization, 2014.

[2] G.R. Mcgregor and J.K. Vanos, Heat: a primer for public health researchers, Public Health. 161(2017)138-146.

[3] S. Rowlinson, A. Yunyanjia, B. Li and C. Chuanjingju, Management of climatic heat stress risk in construction: a review of practices, methodologies, and future research, Accid Anal Prev. 66(3)(2014) 187-198.

[4] T. Kjellstrom, S. Sawada, T.E. Bernard, K. Parsons, H. Rintamäki and I. Holmér, Climate change and occupational heat problems, Ind Health. 51(1)(2013) 1-2.

[5] T. Kjellstrom, B. Lemke and M. Otto, Mapping occupational heat exposure and effects in SouthEast Asia: ongoing time trends 1980-2011 and future estimates to 2050, Ind Health. 51(1)(2013) 56-67.

[6] P.A. Schulte and H. Chun, Climate change and occupational safety and health: establishing a preliminary framework, J Occup Environ Hyg. 6(9)(2009) 542-554.

[7] B.M. Varghese, A. Hansen, B. Peng and D. Pisaniello, Are workers at risk of occupational injuries due to heat exposure? A comprehensive literature review, Safety Sci. 110(part A)(2018)380-392.

[8] K. Lundgren, K. Kuklane, C. Gao and I. Holmér, Effects of heat stress on working populations when facing climate change, Ind Health. 51(1)(2013) 3-15.

[9] H. Heidari, F. Golbabaei, A. Shamsipour, F.A. Rahimi and A. Gaeini, Outdoor occupational environments and heat stress in IRAN, J Environ Health Sci Engineer. 13(1)(2015) 48-55.

[10] L.L. Jackson and H.R. Rosenberg, Preventing heat-related illness among agricultural workers, J 
Agromedicine. 15(2010) 200-215.

[11] Y. Xu and A.P.C. Chan, An investigation of heat related incidents on construction workers in Hong Kong, The 19th Cross-strait conference on occupational safety and health, Hong Kong, 3rd November, 2011.

[12] I. Ryoichi, K. Junichi and M. Seyed Mohammad, Comparison of subjective symptoms and cold prevention measures in winter between traffic control workers and construction workers in Japan, Ind Health. 45(1)(2007) 91-99.

[13] V.F. Nunfam, J. Oosthuizen, K. Adusei-Asante, E.J. Van Etten, K. Frimpong, Perceptions of climate change and occupational heat stress risks and adaptation strategies of mining workers in Ghana, Sci Total Environ. 657(2019) 365-378.

[14] G. Havenith and D. Fiala, Thermal Indices and Thermophysiological Modeling for Heat Stress, Compr Physiol. 6(1)(2015):255-302.

[15] K.C. Parsons, Human thermal environments: the effects of hot, moderate, and cold environments on human health, comfort, and performance. CRC Press, London, 2014.

[16] S. Coccolo, J. Kämpf, J.L. Scartezzini and D. Pearlmutter, Outdoor human comfort and thermal stress: A comprehensive review on models and standards, Urban Climate. 18(2016):33-57.

[17] K.C. Parsons, Human heat stress, CRC Press, London, 2019.

[18] G.P. Bates and J. Schneider, Hydration status and physiological workload of UAE construction workers: A prospective longitudinal observational study, J Occup Med Toxicol. 3(1)(2008) 21-30.

[19] ISO 7243 Hot Environments-Estimation of the Heat Stress on Working Man, Based on the WBGTIndex (Wet Bulb Globe Temperature). In: International Standardization Organization, Geneva, 1989.

[20] M. Hamerezaee, S.F. Dehghan, F. Golbabaei, A. Fathi, L. Barzegar, and N. Heidarnejad, Assessment of Semen Quality among Workers Exposed to Heat Stress: A Cross-Sectional Study in a Steel Industry, Safety and Health at Work. 9(2)(2017):232-235.

[21] D.S. Moran, A. Shitzer and K.B. Pandolf, A physiological strain index to evaluate heat stress, Am J Physiol. 275(2)(1998) 129-34.

[22] S.J. Petruzzello, J.I. Gapin, E. Snook and D.L. Smith, Perceptual and physiological heat strain: examination in firefighters in laboratory- and field-based studies, Ergonomics. 52(6)(2009) 747-754.

[23] P. Tikuisis, T.M. Mclellan and G. Selkirk, Perceptual versus physiological heat strain during exercise-heat stress, Med Sci Sports Exerc. 34(9)(2002) 1454-1461.

[24] K. Fabbri, Indoor Thermal Comfort Perception - A Questionnaire Approach Focusing on Children, Springer International Publishing AG, Cham, Switzerland, 2016.

[25] J. Malchaire, A. Piette, B. Kampmann, P. Mehnert, H. Gebhardt, G. Havenith, H.E. Den, I. Holmer, K. Parsons and G. Alfano, Development and validation of the predicted heat strain model, Ann Occup Hyg. 45(2)(2001) 123-135.

[26] ISO 7933. Hot Environments-Analytical Determination and Interpretation of Thermal Stress Using Calculation of Required Sweat Rate, In: International Standardization Organization, Geneva, 1989.

[27] ISO 7933. Ergonomics of the thermal environment analytical determination an interpretation of heat stress using calculation of the predicted heat strain, In: International Standardization Organization, Geneva, 2004.

[28] I. Holmér, Climate change and occupational heat stress: methods for assessment, Glob Health Action. 3(2010) 5719-5723.

[29] K. Lundgren-Kownacki, N. Martã Nez, B. Johansson, A. Psikuta, S. Annaheim and K. Kuklane, Human responses in heat - comparison of the Predicted Heat Strain and the Fiala multi-node model for 
a case of intermittent work, J Therm Biol. 70(Pt A)(2017) 45-52.

[30] P. Bröde, D. Fiala, B. Lemke and T. Kjellstrom, Estimated work ability in warm outdoor environments depends on the chosen heat stress assessment metric, Int J Biometeorol. 62(4)(2017) 1-15. [31] K.P. Singh, Occupational health impacts of climate change: current and future ISO standards for the assessment of heat stress, Ind Health. 51(1)(2013) 86-100.

[32] F. Wang, K. Kuklane, C. Gao, and I. Holmér, Can the PHS model (ISO7933) predict reasonable thermophysiological responses while wearing protective clothing in hot environments? Physiol Meas. 32(2)(2011) 239-249.

[33] R. Ma, S. Zhong, M. Morabito, S. Hajat, Z.W. Xu, Y.L. He, J.Z. Bao, R.R. Sheng, C.C. Li, C.H. Fu and C.R. Huang, Estimation of work-related injury and economic burden attributable to heat stress in Guangzhou, China, Sci Total Environ. 666(2019) 147-154.

[34] ISO 8996. Ergonomics of the thermal environment: determination of metabolic rate, In: International Standardization Organization, Geneva, 2004.

[35] Z. Jing, N. Zhu, and S. Lu, Productivity model in hot and humid environment based on heat tolerance time analysis, Build Environ. 44(11)(2009) 2202-2207.

[36] G. Guo, High temperature Physiology and Health, Shanghai Science and Technology Press, Shanghai, 1989. (In Chinese).

[37] GB/T 934. Methods for measuring meteorological conditions in the hot work environment, In: Standardization Administration Of China, Beijing, 2008.

[38] American College of Sports (ACSM), Prevention of thermal injuries during distance running, Med Sci Sport Exer. 16(5)(1984) 427-443.

[39] F. Faul, E. Erdfelder, A.G. Lang and A. Buchner, G*Power 3: A flexible statistical power analysis program for the social, behavioral, and biomedical sciences, Behav Res Methods. 39(2)(2007) 175-191. [40] World Medical Association(WMA), WMA Declaration of Helsinki - Ethical Principles for Medical Research Involving Human Subjects, in 64th WMA General Assembly, Fortaleza, Brazil, October 2013. [41] World Health Organization(WHO), Health factors involved in working under conditions of heat stress, WHO Publications, 1969.

[42] N.L. Ramanathan, A new weighting system for mean surface temperature of the human body, J Appl Physiol. 19(19)(1964)531.

[43] C.A. Machado-Moreira, F.D.C. Magalhães, A.C. Vimieiro-Gomes, N.R.V. Lima, and L.O.C. Rodrigues, Effects of heat acclimation on sweating during graded exercise until exhaustion, J Therm Biol. 30(6)(2005) 437-442.

[44] Z. Tian, N. Zhu, G. Zheng, and H. Wei, Experimental study on physiological and psychological effects of heat acclimatization in extreme hot environments, Build Environ. 46(10)(2011) 2033-2041.

[45] D.G. Altman and J.M. Bland, Measurement in Medicine: The Analysis of Method Comparison Studies, J R Stat Soc Series D. 32(3)(1983) 307-317.

[46] D.G. Altman and J.M. Bland, Statistical methods for assessing agreement between two methods of clinical measurement, Lancet. 1(8476)(1986) 307-310.

[47] J.M. Bland and D.G. Altman, Measuring agreement in method comparison studies, Stat Methods Med Res. 8(2)(1999) 135-160.

[48] R. Zaki, A. Bulgiba, R. Ismail, and N.A. Ismail, Statistical methods used to test for agreement of medical instruments measuring continuous variables in method comparison studies: a systematic review, Plos One. 7(5)(2012) e37908.

[49] ISO 9886. Ergonomics-Evaluation of thermal strain by physiological measurements, In: 
International Standardization Organization, Geneva, 2004.

[50] S. Robinson, E.S. Turrell and S.D. Gerking, Physiologically Equivalent Condition of Air Temperature and Humidity, Am J Physiol. 143(1)(1945) 21-32.

[51] P.O. Astrand and B. Saltin, Maximal oxygen uptake and heart rate in various types of muscular activity, J Appl Physiol. 16(6)(1961) 977-981.

[52] A. Frank, M. Belokopytov, Y. Shapiro and Y. Epstein, The cumulative heat strain index-a novel approach to assess the physiological strain induced by exercise-heat stress, Eur J Appl Physiol. 84(6)(2001) 527-532.

[53] K Wasserman, J.E. Hansen, D.Y. Sue, Principles of exercise testing and interpretation: including pathophysiology and clinical applications (5th ed), Lippincott Williams \& Willkins Philadelphia, USA, 2005.

[54] G. Havenith, I. Holmér and K. Parsons, Personal factors in thermal comfort assessment: clothing properties and metabolic heat production, Energ Build. 34(6)(2002) 581-591.

[55] S. Rowlinson, A. Yunyanjia, B. Li and C. Chuanjingju, Management of climatic heat stress risk in construction: A review of practices, methodologies, and future research, Accid Anal Prev. 66(3)(2014) $187-198$

[56] Y. Epstein and D.S. Moran, Thermal comfort and the heat stress indices, Ind Health. 44(3)(2006) 388-398.

[57] R. Yao, Y. Li, C. Du and B. Li, A heart rate-based model ( $\left.\mathrm{PHS}_{\mathrm{HR}}\right)$ for predicting personal heat stress in dynamic working environments, Build Environ. 135(2018)318-329.

[58] T. Miyamoto, Y. Oshima, K. Ikuta, and H. Kinoshita, The heart rate increase at the onset of highwork intensity exercise is accelerated by central blood volume loading, Eur J Appl Physiol. 96(1)(2006) 86-96.

[59] A. Psikuta, R. Niedermann and R.M. Rossi, Effect of ambient temperature and attachment method on surface temperature measurements, Int J Biometeorol. 58(5)(2014) 877-885.

[60] M. Luo, Z. Wang, K. Ke, B. Cao, Y. Zhai and X. Zhou, Human metabolic rate and thermal comfort in buildings: The problem and challenge, Build Environ. 131(2018) 44-52.

[61] J. Kim, S. Schiavon and G. Brager, Personal comfort models-A new paradigm in thermal comfort for occupant-centric environmental control, Build Environ. 132(2018)114-124.

[62] J.D. Périard, G.J.S. Travers, S. Racinais, and M.N. Sawka, Cardiovascular adaptations supporting human exercise-heat acclimation, Auton Neurosci. 196(2016) 52-62.

[63] H. Pallubinsky, B.R.M. Kingma, L. Schellen, B. Dautzenberg, M.A.V. Baak, and W.D.V.M. Lichtenbelt, The effect of warmth acclimation on behaviour, thermophysiology and perception, Build Res Inform (2017) 1-8.

[64] J.D. Périard, G.J.S. Travers, S. Racinais and M.N. Sawka, Cardiovascular adaptations supporting human exercise-heat acclimation, Auton Neurosci. 196(2016) 52-62. 


\section{Appendix A.1 Prediction validation of the PHS model on Tsk}
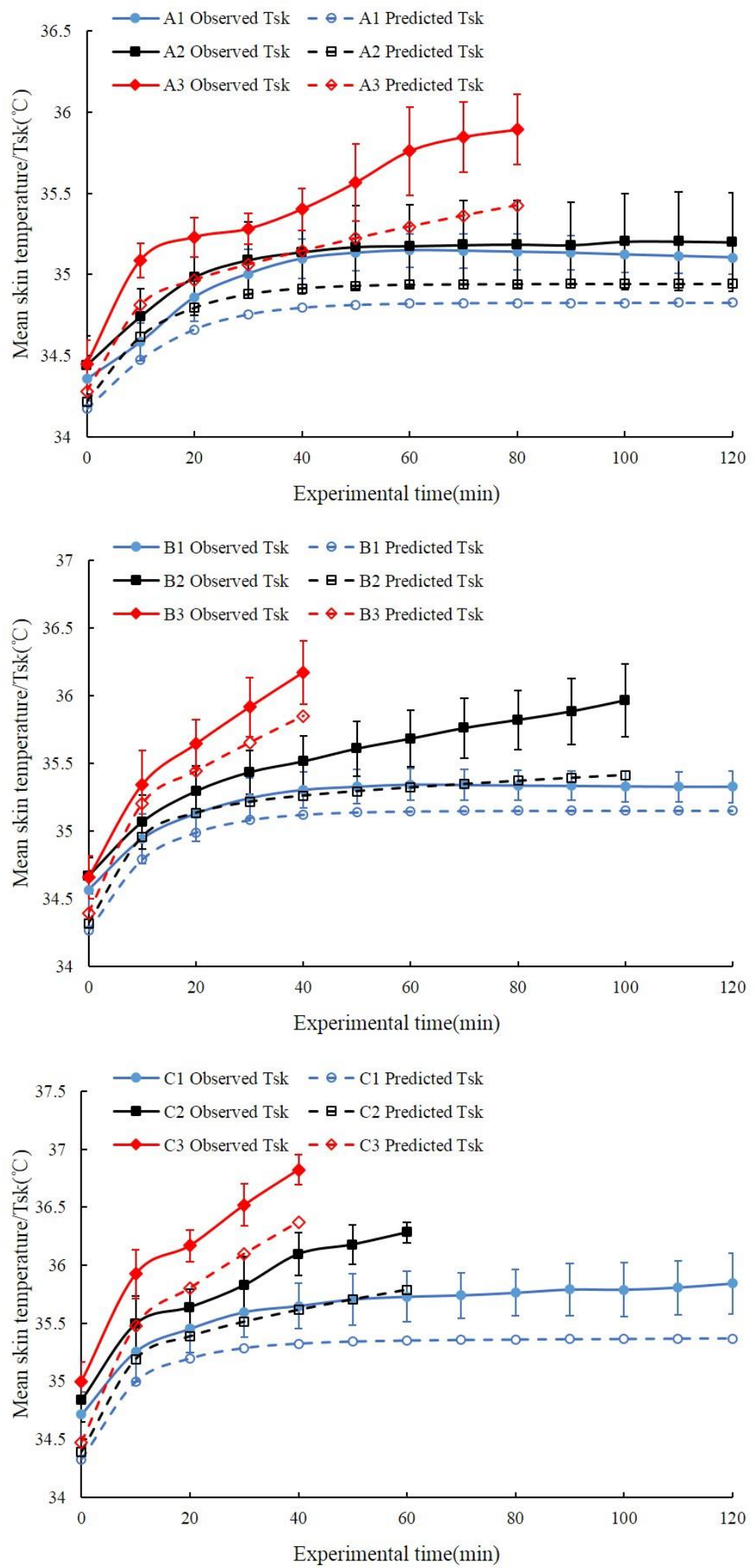
Appendix A.2 Prediction validation of the PHS model on SR

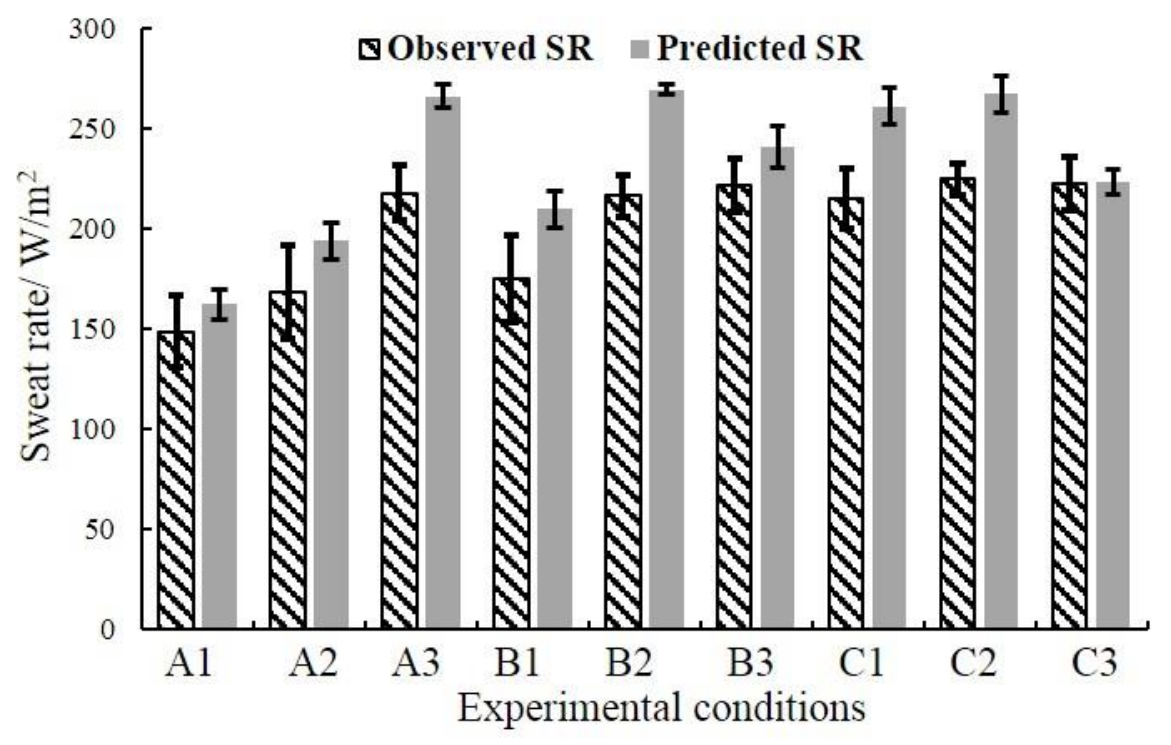




\section{Appendix B.1 Tsk verification using Bland-Altman analysis}
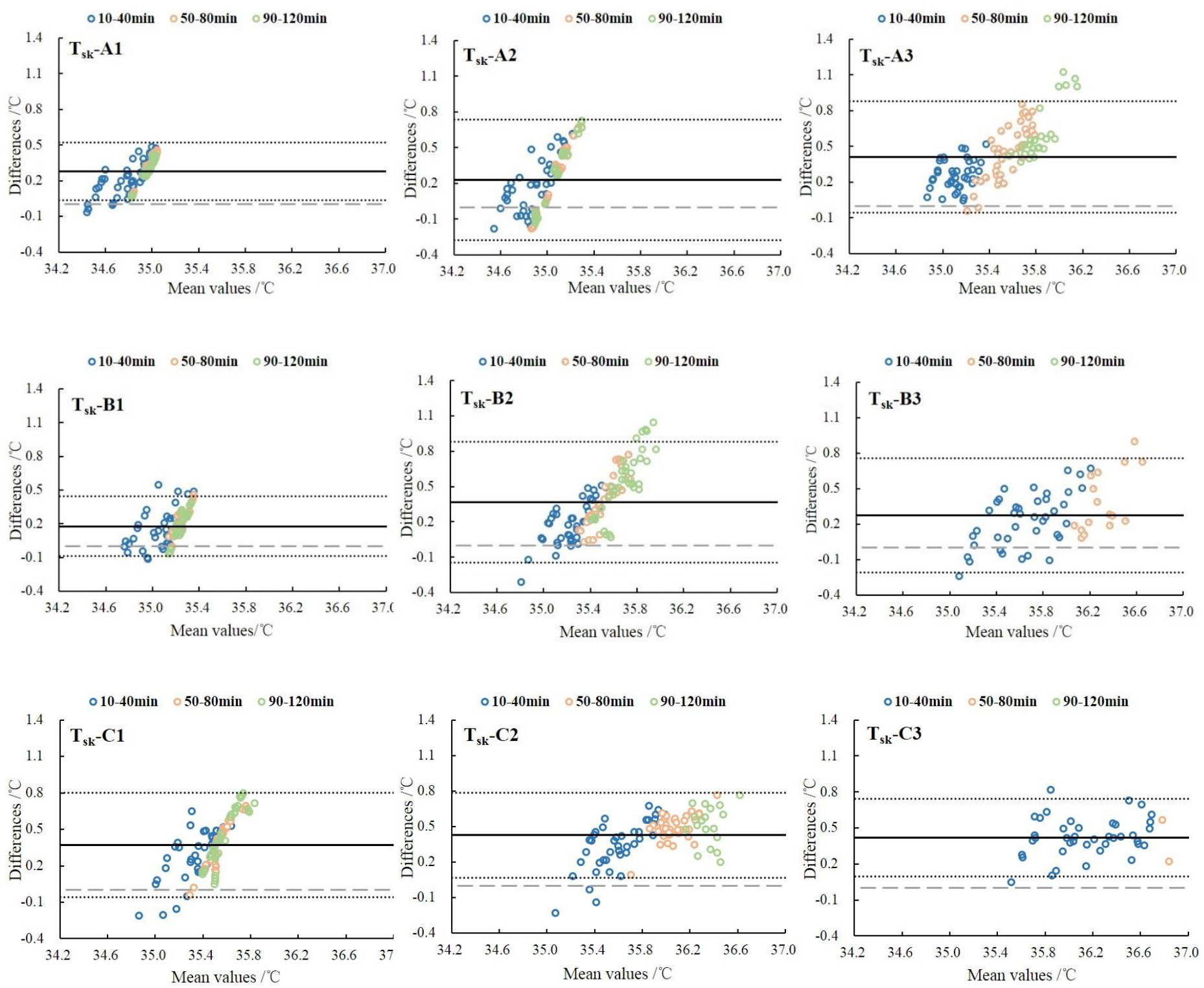

(Note: The difference value in the Y-Axis is defined as $\left(\mathrm{Tsk}_{\mathrm{o}}-\mathrm{Tsk}_{\mathrm{p}}\right)$ and the mean value in the $\mathrm{X}$-Axis is defined as $\left.\left(\mathrm{Tsk}_{\mathrm{o}}+\mathrm{Tsk}_{\mathrm{p}}\right) / 2\right)$ 